\title{
Strategic decentralization and the provision of global public goods*
}

\author{
Renaud Foucart ${ }^{\dagger} \quad$ Cheng Wan ${ }^{\ddagger}$
}

August 22, 2017

We study strategic decentralization in the provision of a global public good. A federation, with the aim of maximizing the aggregate utility of its members, may find it advantageous to decentralize the decision-making, so that its members act autonomously to maximize their own utility. If utility is fully transferable within a federation, the larger a federation is or the more sensitive it is to the public good, the more it has incentives to remain centralized. If an overall increase in the sensitivity to the public good induces some federation(s) to decentralize, it may lead to a decrease in the aggregate provision. With non-transferable utility within a federation, those members that are smaller or less sensitive to the public good are more likely to prefer decentralization. Some members within a federation becoming more sensitive to the public good may thus lead to a lower aggregate provision, because the increased heterogeneity of the federation makes it more inclined to decentralize.

JEL: C72, H41

Keywords: Global public goods, Decentralization, Delegation.

\footnotetext{
*We thank Paola Conconi, Grégoire Garsous, Victor Ginsburgh, Georg Kirchsteiger, Patrick Legros, Debraj Ray, Till Requate, André Sapir, Anja Schöttner, Annalisa Vinella and two anonymous referees for useful comments and discussion.

${ }^{\dagger}$ Humboldt University, Berlin, renaud.foucart@hu-berlin.de

${ }^{\ddagger}$ Corresponding author. School of Public Economics and Administration, Shanghai University of Finance and Economics, cheng.wan.2005@polytechnique.org
} 


\section{Introduction}

Contribution to global public goods, such as mitigation of climate change, production of scientific knowledge, international security or preservation of natural resources, is one of the domains where international cooperation matters the most. Yet, on many of these issues, even existing federations of states or countries often choose to act in a decentralized way, such as for military interventions in the European Union or climate policy in the United States.

In this paper, we study the causes and consequences of strategic decentralization. We set up a model where pre-existing federations noncooperatively contribute to a global public good. The game takes place over two stages. In the second stage, centralized federations and individual countries play a non-cooperative global public goods game. In the first stage, the members of each federation jointly choose a political structure, according to which the decision of the provision of the public good is then made within the federations. If the members of a federation choose to provide the good in a centralized way, they delegate the voluntary provision to a centralized level, which maximizes their total surplus. If they choose to provide the good in a decentralized way, each member maximizes its own surplus independently by choosing its contribution. The choice of the political structure generates a trade-off. Being centralized, a federation internalizes the externalities caused by the public good production within the federation. Being decentralized, a federation commits itself to free riding on the other one.

First, we study the impact of different political structures on the provision of the public good, as well as the factors that make unilateral decentralization beneficial to a federation. Secondly, we solve a game where federations simultaneously choose their political structure with fully transferable utility within each federation (TU). We show that federations which are larger or more sensitive to the public good have stronger incentives to remain centralized. An overall increase in the sensitivity to the public good may however lead to a lower total production of public good, because it influences the players' strategic incentives to decentralize. Thirdly, we compare these results with a setup characterized by non-transferable utility (NTU). While the trade-offs identified in the TU case remain, sensitivity to the public good now plays an additional role, since smaller and less sensitive members are more likely to prefer decentralization. All other things equal, a more heterogeneous federation is thus more prone to decentralize. Being a heterogeneous federation may therefore be a strategic advantage if utility is non-transferable.

Our modeling approach differs from the traditional view of coalition formation according to which individual actors seek to cooperate with each 
other on a single issue (see, for instance, d'Aspremont et al., 1983, Bloch, 1996 and Ray and Vohra, 1997). ${ }^{1}$ In contrast, we start by assuming that countries belong to pre-existing federations - bounded by a common history of cooperation, shared interest, or mutual trust - and are able to choose the institutional design to maximize their combined surplus. For instance, member states of the European Union have to agree with each other on which institutional level should be in charge of determining the amount of military contributions or pollution abatements within the union. But we assume each of these issues alone does not determine which countries leave or join the European Union. In this sense, our approach adds an additional layer to the literature on coalition formation, by understanding and modeling how single players (that are exogenously given in most of the coalition-formation models) come about.

Once an institution exists, and the mutual trust between its members is present, nothing prevents them from voting unanimously to extend the scope of the institution's intervention. When a federation can truthfully design transfers among its members (TU), it is possible to centralize on an issue that would otherwise create winners and losers (see Kosfeld et al., 2009). For instance, the common agricultural policy was a unanimous choice to extend the scope of the European Union, while the British government managed to receive a rebate on its contribution to the European Union budget as a compensation. ${ }^{2}$ Enforcement of an agreement outside a federation is however particularly complicated. The absence of enforcement is often described as the main weakness of global international environmental agreements (see for instance Chapter 15 of Barrett, 2003, and Nordhaus, 2015).

Although federations exist and are relatively stable over time, it is a striking fact that they often act in a decentralized way on specific global issues. For instance, the United States is a federal country whose centralized level of government takes decisions on several global issues, such as national defense. However, regarding global climate change, the policy of

\footnotetext{
${ }^{1} \mathrm{Yi}$ (1997) presents number of properties of those different coalition-formation rules, in the presence of either positive or negative externalities. Belleflamme (2000) allows for asymmetric countries in an open membership game with negative externalities and McGinty (2007) for one with positive externalities. Some of these models have been applied to the context of climate change and global pollution (see for instance Carraro and Siniscalco, 1993, Barrett, 1994 or Barrett, 2005). In a cooperative game setting, Basile et al. (2016) give sufficient conditions for the equivalence between the core and the set of competitive allocations in a mixed market with both individual agents and coalitions, who choose among public projects as well as their contribution to it.

${ }^{2}$ In 1984, the UK negotiated a mechanism (the "Fontainebleau agreement") wherein it automatically gets back about two-thirds of the difference between what it contributes to and what it receives from the EU budget at the end of each year (Lowe et al., 2002).
} 
the United States has always been "bottom up," in that the central government delegates to states the choice of taking constraining decisions on abatement targets (Lutsey and Sperling, 2008). ${ }^{3}$ A consequence is the refusal of the United States administration to commit on abatements, making the European Union complain about the "lack of American Leadership."4

Similarly, individual member countries of the European Union have long acted in a decentralized way on most military interventions (Howorth, 2001; Kirchner, 2006). These include conflicts on the European continent such as the Balkan wars in the 1990s, where most of the leadership was left to the United States (Gordon, 1997, p.74). Since the early 2000s, some smaller-scale military interventions have been made on behalf of the European Union's Common Security and Defense Policy (CSDP) (Kaldor and Salmon, 2006). But when the 2011 crisis in Libya escalated, "no one apparently seriously considered intervention under the framework of the CSDP" and "the European Union stood on the sidelines and watched as France and the United Kingdom, acting within a NATO framework, intervened militarily on the Union's doorstep" (Menon, 2011, p.75).

We review the relevant literature in Section 2. Focusing on subgame perfect Nash equilibria, we start by solving the second stage in Section 3 and then solve the first stage in Section 4. We discuss the case of NTU and that of partial decentralization in Section 5 and conclude in Section 6 .

\section{Related literature}

In this paper, we claim that decentralization can be strategic if it is in the joint interest of the federation members. Decentralization as a means to free ride is derived from the fact that smaller players have fewer incentives to contribute in a non-cooperative game of public goods (see Olson and Zeckhauser, 1966, and the more recent discussion in Buchholz and Sandler, 2016). In addition to the military and environmental examples described above, the idea that larger players contribute more has also been largely explored in trade agreements. For instance, Ludema and Mayda (2009) show that when free riding on trade agreements is possible (the Most Favored Nation clause of the WTO/GATT), each exporting country's willingness to bear the cost of participating in negotiations depends on its market share, so that the "smallest" countries free ride on others.

The literature on fiscal federalism has generally taken as given that public goods (such as national defense) were precisely the cause of the formation

\footnotetext{
${ }^{3}$ The US government seems, however, able to deal in an efficient and centralized way on environmental issues with a national impact only, such as acid rains, as shown by the Bush senior administration in the early 1990s (Joskow et al., 1998).

${ }^{4}$ Andreas Carlgren, Sweden's Environment Minister talking on behalf of the EU presidency (Copenhagen talks, 2009, cited by The Guardian, November 2, 2009).
} 
of a federation (Oates, 2005, p.366), but not a cause of secession or decentralization. Economists have long been interested in the formation and the maintenance of cartels producing public goods. The generally studied procedure of coalition formation is a bottom-up two-stage game. In the first stage, countries decide whether or not to join a coalition. In the second stage, each coalition acts as a single player who maximizes the aggregate welfare of its members. This setting presumes that, conditional on being members of a coalition, countries are able to sign binding contracts and punish deviators. Since individual countries have a strong incentive to free ride, these models generally predict that International Environmental Agreements (IEAs) can achieve little more than a non-cooperative framework (Barrett, 2005).

Nevertheless, in a global public goods game, the coalition maximizing the aggregate welfare of all the players (i.e. the grand coalition) should be feasible with transfers and/or credible punishment of deviators (see Carraro and Siniscalco, 1993 and Carraro et al., 2006 for a discussion of this argument). ${ }^{5}$ There must however be a history of sequential commitments, in the sense that a first group of countries commit themselves to acting together, and then jointly choose to expand the coalition by providing a transfer to an additional member. Ray and Vohra (2001) show that the existence of transfers is not sufficient to ensure the formation of the grand coalition, when countries are free to sequentially offer a new partition, even after entering a coalition.

Our approach is closer to the top-down "club" coalitions in Nordhaus (2015), with multiple clubs. Similar to this paper, we assume enforcement is possible among the members of the clubs, and among these members only. However, in Nordhaus' framework, TU does not justify the assumption that heterogeneous members of the club can maximize its joint surplus, because each member can make a transfer proposal, which leads to instability. In contrast, we assume a federation is an existing entity with an identified leadership, able to maximize joint surplus and ensure participation of all via transfers, very much like the head of a household in Bergstrom (1989).

Our contribution furthermore belongs to a growing literature which enriches the structure of the players involved in international cooperation. For instance, Köke and Lange (2017) consider the political economy within countries as a driving force of the scope and size of climate agreements, and Marchiori et al. (2017) study the game between lobbies and governments to explain why the latter may want to use climate agreements in order to improve their bargaining position. Interpreting our approach in the language of coalition-formation literature, a federation can be seen as a

\footnotetext{
${ }^{5}$ Most of the environmental literature focuses on a single coalition. In an open membership game, multiple coalitions may coexist in equilibrium, but must be stand-alone stable, in the sense that no individual should be better off by deviating (Yi, 1997).
} 
focal point which is reachable if it is in the interest of all the member countries. Our difference with an open-membership IEA à la d'Aspremont et al. (1983), as used for instance by Barrett (1994), is that possible members of the federation are clearly identified. This mitigates one of the problems leading to the lack of cooperation in IEAs: in d'Aspremont et al. (1983), if one member of a large cartel quits, the cartel is maintained until it shrinks to its (minimal) stable size. At this moment, no outside player wants to join. Each remaining member knows that their withdrawal from the cartel will make it explode. Hence, when agreements exist, they are often of (endogenously) small size. In our setting, a federation leader makes a takeit-or-leave-it offer to its well-identified members. By refusing to be part of a large agreement, each individual member is in a position to destroy the cartel.

The result of profitable decentralization is reminiscent of at least two important results in Industrial Organization. First, Salant et al. (1983) show that in a Cournot environment, a horizontal merger may lower the profits of firms. Secondly, in a similar environment, Baye et al. (1996) show that large firms may benefit from divisionalisation and franchising. If a firm can ex-ante commit itself to delegating the production choice to several smaller franchises, this is equivalent to a commitment to a higher level of production. A rather similar intuition also exists in congestion games: Sorin and Wan (2013) show that a player may benefit from "delegating" itself and not internalizing the congestion externality.

Our focus is also close to two papers on the link between country size, centralization and the provision of global public goods. First, Eckert (2003) shows that with exogenous constitution (the choice of centralization), a decentralized country may benefit from a better position in the negotiation over a climate agreement, for its disagreement point is more favorable. She builds a model with two federations, each composed of a single polluting region and some identical, non-polluting members. A federation can be either centralized or decentralized. She studies a bilateral agreement modeled as a Nash bargain without transfers, and provides an example of a strategic game of decentralization in this context. In contrast, we study a game in which federations of possibly different size and sensitivity strategically choose their political structure before non-cooperatively contributing to the public good, and compare transferable and non-transferable utility within the federation. This allows us to understand in a more precise way the possible equilibria, and to study the impact of a change in the sensitivities to the public good. Second, Buchholz et al. (2014) show that if a group of countries can choose a matching ratio for their contributions to a public good, the existence of a coalition may decrease the aggregate level of public good. However, this paper does not study strategic interaction 
among federations beyond the last stage of contribution to the global public good .

\section{Last stage: Voluntary provision of public goods}

To solve the two-stage decentralization game by backward induction, we begin the analysis by the last stage. The players in this stage play a game of voluntary provision of a public good (Bergstrom et al., 1986).

There are $N$ players, indexed by $i \in \mathcal{N}=\{1, \ldots, N\}$. A player $i$ is either an autonomous country, or a centralized federation composed of a finite number $n_{i} \geq 2$ of member countries. Each country $k$, autonomous or not, is characterized by its size $m_{k}$ and its sensitivity to the public good $s_{k}$. We denote the set of member countries of federation $i$ by $F_{i}$ and the set of all the countries by $\mathcal{F}$. To simplify the notation, we consider an autonomous country $i$ as a federation consisting of only one country, so that $F_{i}=\{i\}$.

An autonomous country $i$ chooses its contribution of public good $Q_{i} \geq 0$. Being interested in how the political structure affects the production of public good, we consider contribution of a country as proportional to its size. In other words, we focus on $q_{i}=\frac{Q_{i}}{m_{i}}$, the per-unit contribution of country $i$, its contribution divided by their size, instead of $Q_{i}$, its total contribution.

A centralized federation $i$ chooses the per-unit contribution of public good $q_{k}$ for each of its member countries $k \in F_{i}$, in order to maximize their aggregate welfare.

The profile of choices is a vector $\mathbf{q}=\left(q_{k}\right)_{k \in \mathcal{F}}$. The aggregate level of the public good is denoted by $Q=\sum_{k \in \mathcal{F}} m_{k} q_{k}$.

The per-unit utility of a country $k \in \mathcal{F}$, when the players' strategy profile is $\mathbf{q}$, is

$$
v_{k}(\mathbf{q})=s_{k} B(Q)-C\left(q_{k}\right),
$$

where $B(Q)$ is its benefit from the aggregate level of the public good, and $C\left(q_{k}\right)$ stands for the cost of providing the public good. The (total) utility of country $k$ is simply $m_{k} v_{k}(\mathbf{q})$. Throughout the paper, we assume that $B$ is defined on $[0,+\infty[$, twice continuously differentiable, strictly concave, $B(0)=0$, and $B^{\prime}(0)>0$, while $C$ is defined on $[0,+\infty[$, twice continuously differentiable, strictly increasing and strictly convex, $C^{\prime}(0)=$ 0 , and $C^{\prime}(x) \rightarrow+\infty$ when $x \rightarrow+\infty$.

The fact that the benefit depends on the aggregate level of public good implies that each country's contribution generates a positive externality on all the other countries. The assumptions on $B$ signify marginally decreasing benefit from the aggregate level of public good, whereas those on $C$ signify marginally increasing cost of a country's individual contribution. Finally, 
the more sensitive a country is to the public good, the more utility it derives from the same amount of the public good.

The total utility of a federation $i$ is the sum of those of its members:

$$
V_{i}(\mathbf{q})=\sum_{k \in F_{i}} m_{k} v_{k}(\mathbf{q})
$$

and its per-unit utility is

$$
v_{i}(\mathbf{q})=\frac{V_{i}(\mathbf{q})}{m_{i}}=\sum_{k \in F_{i}} w_{k} v_{k}(\mathbf{q}),
$$

where $m_{i}=\sum_{k \in F_{k}} m_{k}$ is the total size of the federation, and $w_{k}=\frac{m_{k}}{m_{i}}$ is the relative weight of country $k$ in federation $i$.

Denote this public goods game by $G(\mathcal{N})$. A strategy profile $\mathbf{q}$ is a Nash equilibrium if for each player $i \in \mathcal{N}$, its strategy $\mathbf{q}_{i}=\left(q_{k}\right)_{k \in F_{i}} \in \mathbb{R}^{+n_{i}}$ maximizes its per-unit utility, ${ }^{6}$ given $\mathbf{q}_{-i}=\left(q_{1}, \ldots, q_{i-1}, q_{i+1}, \ldots, q_{N}\right)$ :

$$
v_{i}\left(\mathbf{q}_{i}, \mathbf{q}_{-i}\right)=\max _{\mathbf{x} \in \mathbb{R}^{+n_{i}}} v_{i}\left(\mathbf{x}, \mathbf{q}_{-i}\right) .
$$

Lemma 1. The following general properties hold in $G(\mathcal{N})$ :

(i) At any equilibrium $\mathbf{q}$ of the game, a federation $i$ chooses the same per-unit contribution for each of its member countries: $q_{k}=q_{l}$ for all $k, l \in F_{i}$.

(ii) A federation $i$ behaves like an autonomous country with size $m_{i}$ and sensitivity $s_{i}$, where $s_{i}=\sum_{k \in F_{k}} w_{k} s_{k}$ is the weighted average sensitivity of its member countries.

(iii) For two member countries $k$ and $l$ in federation $i$, their per-unit utilities at any equilibrium $\mathbf{q}$ satisfies that $v_{k}(\mathbf{q}) \geq v_{l}(\mathbf{q})$ if and only if $s_{k} \geq s_{l}$.

The proof is in Appendix B. According to this lemma, $G(\mathcal{N})$ can be simply considered as a public goods game played by $N$ players where each player $i$, characterized by $m_{i}$ and $s_{i}$ and behaving like an autonomous country, chooses her per-unit contribution $q_{i}$. Since member states within a federation provide the same per-unit amount of public good, being highly sensitive to the public good is an advantage for a member country, because it benefits more from the aggregate provision while contributing the same, proportionally. On the contrary, their sizes do not matter.

\footnotetext{
${ }^{6}$ Since in this last stage the size of players are given, a player maximizing its per-unit utility is equivalent to maximizing its utility.
} 
Lemma 2. The following general properties hold in $G(\mathcal{N})$ :

(i) The game admits a unique Nash equilibrium. By abuse of notation, let it be denoted by $\mathbf{q}=\left(q_{i}\right)_{i \in \mathcal{N}}$.

(ii) For two players $i$ and $j$, at the equilibrium $\mathbf{q}, q_{i}>q_{j}$ if and only if $s_{i} m_{i}>s_{j} m_{j}$.

(iii) If two players have the same sensitivity to the public good, then the one with larger size has a lower per-unit utility at the equilibrium.

(iv) If two players have the same size, then the one with higher sensitivity to the public good has a higher per-unit utility at the equilibrium.

(v) All other things held equal, a player $i$ provides more public good $Q_{i}$ at the equilibrium when its size $m_{i}$ increases, and less per-unit public good $q_{i}$ at the equilibrium when the size of any other player $m_{j}$ increases: $\frac{\Delta Q_{i}}{\Delta m_{i}}>0, \frac{\Delta Q_{i}}{\Delta m_{j}}<0$.

(vi) All other things held equal, a player $i$ provides more per-unit public good $q_{i}$ at the equilibrium when its sensitivity to the public good $s_{i}$ increases, and less per-unit public good at the equilibrium when the sensitivity of any other player $s_{j}$ increases: $\frac{\Delta Q_{i}}{\Delta s_{i}}>0, \frac{\Delta Q_{i}}{\Delta s_{j}}<0$.

The formal proof is in Appendix B. Lemma 2.(iii), stating that smaller players free ride more, recovers the well-known result (Olson and Zeckhauser, 1966) that being small is an advantage in a public goods game. Intuitively, the marginal return from a unit of investment in the public good is increasing in the size of a player. Hence, being small is a commitment to investing less in the public good. A small player thus more easily free rides on the others. A large and/or highly sensitive player produces more of the public good. However, size and sensitivity do not affect the equilibrium contributions in the same manner. For a given per-unit contribution, a player becoming larger increases the total production of public good. Hence, the marginal benefit of the last unit of public good perceived by each player mechanically decreases. On the contrary, when the sensitivity of a player increases, it only directly affects its own payoff.

In order to obtain closed form solutions, we use in Propositions 2 and 3 the specific results of a linear-quadratic model with the following functions:

$$
\begin{aligned}
B(Q) & =\alpha Q-\frac{\beta}{2} Q^{2}, \\
C(q) & =\frac{\gamma}{2} q^{2},
\end{aligned}
$$

where $\alpha>0, \beta \geq 0$ and $\gamma>0$ are constants. 
In this case, the explicit expression of contributions of the federations is given by

$$
q_{i}=\frac{\alpha s_{i} m_{i}}{\beta \theta M^{2}+\gamma}, \forall i \in \mathcal{N} ; \quad Q=\frac{\alpha \theta M^{2}}{\beta \theta M^{2}+\gamma}=\frac{\alpha}{\beta+\frac{\gamma}{\theta M^{2}}}
$$

where $M=\sum_{i \in \mathcal{N}} m_{i}$ and $\theta=\sum_{i \in \mathcal{N}} s_{i}\left(\frac{m_{i}}{M}\right)^{2}$. This shows that the perunit contribution of a player is linearly proportional to the product of its size and its sensitivity. Furthermore, by rewriting $q_{i}=\frac{\alpha s_{i} m_{i}}{\beta \sum_{j \in \mathcal{N}} s_{j} m_{j}^{2} M+\gamma}$, we can see how $s_{i}$ and $m_{i}$ enter differently the equilibrium production in the denominator. The reason why $m_{j}$ is squared in the denominator is that it influences the other players twice: once because for a given perunit production it mechanically increases $Q$, and once because being larger increases the incentives for a player $j$ to produce the public good.

Finally, note that in the case of homogeneous sensitivity among all the players, given the total size, the more heterogeneous they are in size (i.e. the smaller $\theta$ is), the less total contribution $Q$ they make to the provision of the public good.

\section{Simultaneous choice of political structure with transferable utility}

\subsection{Decentralization and its impacts}

This section focuses on the first stage of the decentralization game. We first formally describe this two-stage decentralization game $\mathcal{D}$, then provide some results on the externalities that unilateral decentralization generates on the other players as well as on the aggregate provision of the public good, and finally solve for the equilibrium of the two-stage decentralization game with two federations in the linear-quadratic case.

The player set is $\mathcal{N}$ which contains federations and autonomous countries. In the first stage of the decentralization game $\mathcal{D}$, all the federations have two choices: centralization $(C)$ - acting as one player maximizing the aggregate utility of its member countries, and decentralization $(D)$ - letting the member countries act independently. Autonomous countries have only one choice, $C$.

The choices of the federations, denoted by $\mathbf{a}=\left(a_{i}\right)_{i \in \mathcal{N}}, a_{i} \in\{C, D\}$, induce a public goods game, which is to be played in the second stage of $\mathcal{D}$ by the autonomous countries in $\mathcal{N}$, the member countries of the federation(s) having chosen decentralization, and the federation(s) having chosen centralization. Denote the set of these second stage players by $\mathcal{N}^{\mathrm{a}}$, 
possibly different from those of the first stage, $\mathcal{N}$. We provide an example of two-stage decentralization game in Figure 1.

Figure 1: A two-stage decentralization game with two federations, both composed of three identical members.

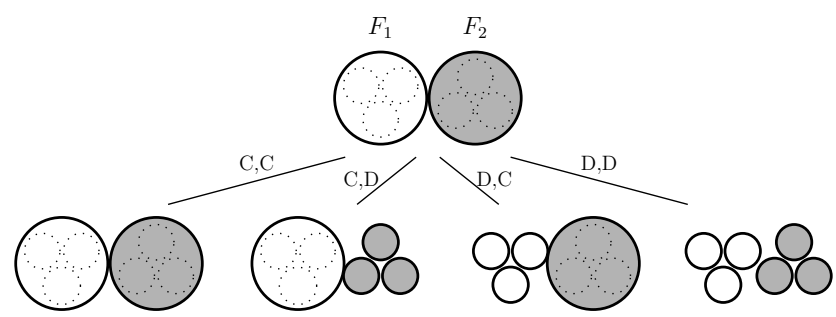

We focus on subgame perfect Nash equilibria (SPNE) of the two-stage game. Hence at the second stage we only consider equilibrium behavior. Section 3 shows that a unique equilibrium exists in the public goods game $G\left(\mathcal{N}^{\mathbf{a}}\right)$. Therefore one can determine, for the first stage, the federations' utilities associated to a pure-strategy profile a.

The average per-unit utility of a centralized federation $i\left(a_{i}=C\right)$ is its equilibrium per-unit utility in the induced public goods game $G\left(\mathcal{N}^{\mathbf{a}}\right)$, denoted by $v_{i}\left(\mathcal{N}^{\mathbf{a}}\right)$ :

$$
u_{i}^{\mathbf{a}}=v_{i}\left(\mathcal{N}^{\mathbf{a}}\right) .
$$

The average per-unit utility of a decentralized federation $j\left(a_{j}=D\right)$ is the weighted average of the equilibrium per-unit utilities of its member countries in $G\left(\mathcal{N}^{\mathbf{a}}\right)$ :

$$
u_{j}^{\mathbf{a}}=\sum_{k \in F_{j}} w_{k} v_{k}\left(\mathcal{N}^{\mathbf{a}}\right)
$$

In our setting, the member countries of a federation make the choice between centralization and decentralization in a fully cooperative way. It can be because these member countries are identical to each other, so that a collective decision can effectively be obtained without controversy. Had countries different sensitivities or sizes, the same results could be obtained using transfers. Indeed, suppose that the sum of the utilities of the members of a decentralized federation acting non cooperatively is higher than the total utility of a centralized federation. Then if the members consensually choose decentralization with additional initial transfers to compensate the losers, then once the federation is decentralized, there is no need for further cooperation among the members. Our assumption of full cooperation among heterogeneous members implies that there exists a leadership of the federation able to maximize joint surplus and make a single transfer offer 
to compensate the potential losers, very much like the head of a household in Bergstrom (1989), to avoid the kind of unstable behavior documented in Nordhaus (2015). We relax the assumption of fully transferable utility (TU) in Section 5.1 to consider the case of non-transferable utility (NTU).

The following proposition summarizes the effects of decentralization. Here, superscript " $(i)$ " is added to all the values in the public goods game after the unilateral decentralization of $i$. We say that a federation is symmetric if its member countries are identical.

Proposition 1. The unilateral decentralization of a federation $i$ has the following effects on the equilibrium of the resulting public goods game $G\left(\mathcal{N}^{(i)}\right)$ :

(i) The aggregate contribution to the public good decreases: $Q^{(i)}<Q$.

(ii) Each of the other players contributes more to the public good while receiving a lower utility: $Q_{j}^{(i)}>Q_{j}, u_{j}^{(i)}<u_{j}$.

(iii) The contribution to the public good from the decentralized federation decreases $Q_{i}^{(i)}<Q_{i}$.

(iv) If a symmetric federation $j$ has the same sensitivity as another symmetric federation $i\left(s_{i}=s_{j}\right)$ but is smaller than $i\left(m_{i}>m_{j}\right)$, while its member countries are not smaller than those of $i$, then $j$ 's unilateral decentralization causes a lower reduction in the aggregate contribution of the public good $Q$ than that of $i: Q^{(i)}<Q^{(j)}$.

(v) If a symmetric federation $j$ is of the same size as another symmetric federation $i\left(m_{i}=m_{j}\right)$ but is less sensitive than $i\left(s_{i}>s_{j}\right)$, while its member countries are not smaller than those of $i$, then its unilateral decentralization causes a lower reduction in the aggregate contribution of the public good $Q$ than that of $i$, if the second derivative of $C$ is non increasing on $\mathbb{R}^{++}: Q^{(i)}<Q^{(j)}$.

The formal proof is in Appendix B. The extension of (i)-(iii) to simultaneous decentralization of several federations is straightforward and is collected in Corollary 1. Also remark that, while Lemma 2 asserts that larger federations and federations more sensitive to the public good contribute more to its provision, (iv) and (v) of Proposition 1 shows that the unilateral decentralization of such federations also exerts greater negative externalities. This is because the decentralization of larger or more sensitive federations works as a commitment to free-riding by those who were most inclined to contribute.

Corollary 1. The simultaneous decentralization of several federations has the following effects on the equilibrium of the resulting public goods games: 
(i) The aggregate contribution to the public good decreases.

(ii) Each player other than the decentralizing federations contributes more to the public good while receiving a lower utility.

(iii) The contribution to the public good from the decentralized federations decreases.

To understand why a certain federation chooses decentralization, consider the condition for a unilateral decentralization to be strictly profitable to federation $i$ :

$$
\sum_{k \in F_{i}} s_{k} w_{k}\left[B\left(\sum_{k \in F_{i}} m_{k} q_{k}^{(i)}+\sum_{l \in \mathcal{N} \backslash\{i\}} m_{l} q_{l}^{(i)}\right)-B\left(\sum_{k \in F_{i}} m_{k} q_{k}^{(i)}+\sum_{l \in \mathcal{N} \backslash\{i\}} m_{l} q_{l}\right)\right]
$$

(6)

$$
\begin{aligned}
& +\sum_{k \in F_{i}} w_{k}\left[C\left(q_{k}\right)-C\left(q_{k}^{(i)}\right)\right] \\
> & \sum_{k \in F_{i}} s_{k} w_{k}\left[B\left(\sum_{k \in F_{i}} m_{k} q_{k}+\sum_{l \in \mathcal{N} \backslash\{i\}} m_{l} q_{l}\right)-B\left(\sum_{k \in F_{i}} m_{k} q_{k}^{(i)}+\sum_{l \in \mathcal{N} \backslash\{i\}} m_{l} q_{l}\right)\right]
\end{aligned}
$$

The left-hand side is the benefit from free riding on the other federations. The first term is the benefits from the increase in the provision of public good by the opponents; the second is the benefit from the lower cost of providing public goods when being decentralized. The right-hand side corresponds to the loss from not internalizing the impact of the public good within the federation.

The following proposition sheds some light on the motivation for decentralization in the special case of linear quadratic utility.

Proposition 2. In the linear-quadratic case, the following is true.

(i) All other things held equal, federation $i$ has more incentives to unilaterally decentralize if either the size or the sensitivity to the public good of another player increases.

(ii) If federation $i$ prefers to decentralize when another federation $j$ is decentralized, then it also prefers to decentralize when $j$ is centralized (other things held equal). Conversely, if federation $i$ prefers to centralize when another federation $j$ is centralized, then it also prefers to centralize when $j$ is decentralized (other things held equal).

The formal proof is in Appendix B. The first statement of Proposition 2 directly derives from condition (6). The larger the size of a federation - or 
the more sensitive it is to the public good - the higher the incentives for another federation to free ride on it, because it is more likely to compensate for the loss of cooperation within the federation. Combining Proposition 1(v) and Proposition 2(i), we see that an increase in the sensitivity of a federation to the public good may well have perverse effects. On the one hand, Proposition 1(v) implies that a more sensitive federation has more incentives to remain centralized. On the other hand, Proposition 2(i) means that an increase in the sensitivity of any other player makes a federation more inclined to decentralize. Hence, if all players see their sensitivity increased, this may well decrease the total production of public good by inducing more decentralization. We provide an example where this is the case in Section 4.3.

\subsection{Two-federation decentralization game}

Return to the two-stage decentralization game $\mathcal{D}$. We consider subgame perfect Nash equilibrium only. Since the equilibrium of the public goods game played in the second stage is unique, we reduce the two-stage game to a normal-form game $\tilde{\mathcal{D}}$ where each player has two choices: centralization and decentralization. A mixed-strategy Nash equilibrium always exists in $\tilde{\mathcal{D}}$. But we are interested in pure-strategy Nash equilibria.

In this subsection, we focus on a decentralization game with two federations. This allows us to have a detailed analysis on the simultaneous, strategic decision on decentralization of more than one player. The matrix in Table 1(b) represents this $2 \times 2$ game corresponding to the first stage of $\mathcal{D}$ in our backward-induction analysis. The row player is federation 1 while the column player is federation 2 .

Table 1: $\tilde{\mathcal{D}}$, the reduced decentralization game.

(a) Per-unit contributions

\begin{tabular}{c|c|c|}
\multicolumn{1}{c}{$C$} & \multicolumn{1}{c}{$D$} \\
\cline { 2 - 3 }$C$ & $q_{1}^{C C}, q_{2}^{C C}$ & $q_{1}^{C D}, q_{2}^{C D}$ \\
\cline { 2 - 3 }$D$ & $q_{1}^{D C}, q_{2}^{D C}$ & $q_{1}^{D D}, q_{2}^{D D}$ \\
\cline { 2 - 3 } & &
\end{tabular}

(b) Per-unit utilities

\begin{tabular}{c|c|c|}
\multicolumn{1}{c}{$C$} & \multicolumn{1}{c}{$D$} \\
\cline { 2 - 3 }$C$ & $u_{1}^{C C}, u_{2}^{C C}$ & $u_{1}^{C D}, u_{2}^{C D}$ \\
\cline { 2 - 3 }$D$ & $u_{1}^{D C}, u_{2}^{D C}$ & $u_{1}^{D D}, u_{2}^{D D}$ \\
\cline { 2 - 3 } & &
\end{tabular}

Corollary 2. In the linear-quadratic case, the possible pure-strategy Nash equilibrium set of the reduced normal-form decentralization game $\tilde{\mathcal{D}}$ is $\{(C, C)\}$, $\{(C, D)\},\{(D, C)\},\{(D, D)\}$ and $\{(C, D),(D, C)\}$.

Corollary 2 follows directly from Proposition 2. In particular, Proposition 2(ii) implies that $(C, C)$ and $(D, D)$ are mutually exclusive as equilibrium. It is a feature of the shape of the benefit function $B^{\prime \prime}<0$, so 
that contributions to the public good are strategic substitutes. There are real world examples where this may not be the case. For instance, in climate change, if there are "tipping points" around which the slope of the marginal benefits change (see for instance Lenton et al., 2008 or Barnosky et al., 2012), there could be strategic complementarities, and it can be worth centralizing only if the other also does so.

We are now ready to give the explicit form of the equilibria of the reduced normal-form decentralization game $\tilde{\mathcal{D}}$ in the linear quadratic case. According to the proof of Proposition 2, eight parameters completely determine the equilibria: $m_{i}, s_{i}, \theta_{i}=\sum_{k \in F_{i}} s_{k} w_{k}^{2}, \xi_{i}=\sum_{k \in F_{i}} s_{k}^{2} w_{k}^{3}$ for $i=1,2$. In order to display the distribution of the different possible equilibria in the space parameterized by these variables, we choose to reduce its dimension by removing asymmetry within a federation and focusing on the role of the size and average sensitivity of each federation only. Since this section assumes transferable utilities within federations, the individual sensitivity and size of each member country are not particularly important. Indeed, a federation makes its decision based on the aggregate utility of its members. We thus consider the case where both federations are symmetric, and the member countries of both federations all have the same size normalized to 1 . In this way, only four parameters determine the equilibria: $n_{1}, n_{2}$ for the sizes of the two federations, and $s_{1}, s_{2}$ for the respective common sensitivities of their member countries. In this case, the member countries of federation 1 (resp. 2) have the same per-unit contribution to the public good when it is decentralized, which is denoted by $q_{i}^{D a_{2}}$ (resp. $q_{j}^{a_{1} D}$ ) as shown in the matrix in Table 1(a).

Finally, in this paper we consider only generic games, in the sense that the four payoffs of each player in Table 1 are all distinct.

Proposition 3. Let federations 1 and 2 be both symmetric and composed by unit-size member countries, characterized by $\left(n_{1}, s_{1}, n_{2}, s_{2}\right) \in \mathcal{N}^{*} \times \mathbb{R}^{++} \times$ $\mathcal{N}^{*} \times \mathbb{R}^{++}$and $n_{1}>1$. Consider the reduced normal-form decentralization game $\tilde{\mathcal{D}}$ with linear quadratic utilities. The pure-strategy equilibria are as follows:

- If $\Gamma_{3}<s_{2}<\Gamma_{1}$, then the unique equilibrium is $(C, C)$.

- If $\Gamma_{2}<s_{2}<\Gamma_{4}$, then the unique equilibrium is $(D, D)$.

- If $s_{2}<\min \left\{\Gamma_{2}, \Gamma_{4}\right\}$ or if $s_{2}<\min \left\{\Gamma_{1}, \Gamma_{3}\right\}$, then the unique equilibrium is $(C, D)$.

- If $s_{2}>\max \left\{\Gamma_{2}, \Gamma_{4}\right\}$ or if $s_{2}>\max \left\{\Gamma_{1}, \Gamma_{3}\right\}$, then the unique equilibrium is $(D, C)$.

- If $\max \left\{\Gamma_{1}, \Gamma_{4}\right\}<s_{2}<\min \left\{\Gamma_{2}, \Gamma_{3}\right\}$, then the pure-strategy equilibria are $(C, D)$ and $(D, C)$. 
where $\Gamma_{i}\left(n_{1}, n_{2}, s_{1}\right), i \in\{1,2,3,4\}$ are explicitly provided in Appendix $B$.

The formal proof is in Appendix B. The function $\Gamma_{1}$ denotes all values of $s_{2}$ such that $u_{1}^{C C}=u_{1}^{D C}$. For any $s_{2}<\Gamma_{1}$ federation 1 prefers to remain centralized in front of a centralized federation 2. By Proposition 2, this implies that being centralized is a dominant strategy for federation 1. Similarly, $\Gamma_{3}$ denotes all the values of $s_{2}$ such that $u_{2}^{C C}=u_{1}^{C D}$. For $s_{2}>\Gamma_{3}$, being centralized is a dominant strategy for federation 3. Hence, for all $\left.s_{2} \in\right] \Gamma_{3}, \Gamma_{1}[$, the unique equilibrium is $(C, C)$.

The functions $\Gamma_{2}$ and $\Gamma_{4}$ correspond respectively to $u_{1}^{C D}=u_{1}^{D D}$ and $u_{2}^{D C}=u_{2}^{D D}$. For all values of $s_{2}>\Gamma_{2}$, federation 1 prefers to decentralize even if federation 2 is decentralized. Hence, decentralizing is a dominant strategy. Similarly, for all values of $s_{2}<\Gamma_{4}$ decentralization is a dominant strategy for federation 2. Hence, for all $\left.s_{2} \in\right] \Gamma_{2}, \Gamma_{4}[$, the unique equilibrium is $(D, D)$.

Condition $s_{2}<\min \left\{\Gamma_{2}, \Gamma_{4}\right\}$ means that decentralizing is a dominant strategy for federation 2 but not for federation $1, s_{2}<\min \left\{\Gamma_{1}, \Gamma_{3}\right\}$ means that centralizing is a dominant strategy for federation 1 , but not for federation 2. In both cases, there is only one equilibrium in the game, $(C, D)$ in which federation 1 centralizes and federation 2 decentralizes. Similarly, if decentralizing is a dominant strategy for federation 1 but not federation 2 $\left(s_{2}>\max \left\{\Gamma_{2}, \Gamma_{4}\right\}\right)$ or if centralizing is a dominant strategy for federation 2 but not federation $1\left(s_{2}>\max \left\{\Gamma_{1}, \Gamma_{3}\right\}\right)$, the unique equilibrium is $(D, C)$.

Finally, if no federation has a dominant strategy $\left(\max \left\{\Gamma_{1}, \Gamma_{4}\right\}<s_{2}<\right.$ $\min \left\{\Gamma_{2}, \Gamma_{3}\right\}$ ), the game displays multiple equilibria in which one federation remains centralized while the other decentralizes.

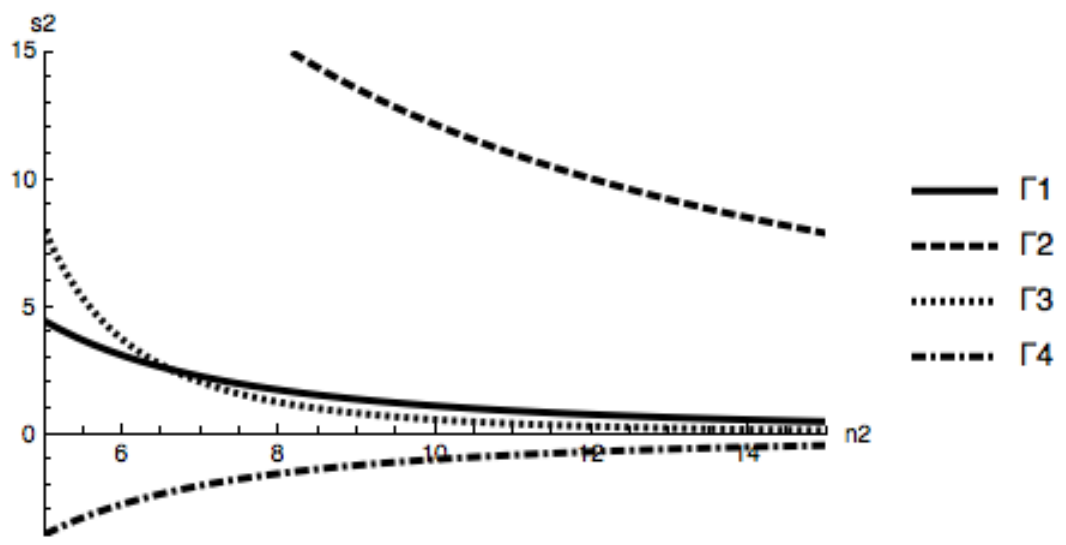

Figure 2: Characterizing $\Gamma_{i}$ with $\alpha=\gamma=s_{1}=1, \beta=0.01, n_{1}=10$.

Figures 2 and 3 represent a linear-quadratic case where the concavity of the benefit curve is low $\left(-B^{\prime \prime}=\beta=0.01\right)$. For all values of $s_{2}$ below 


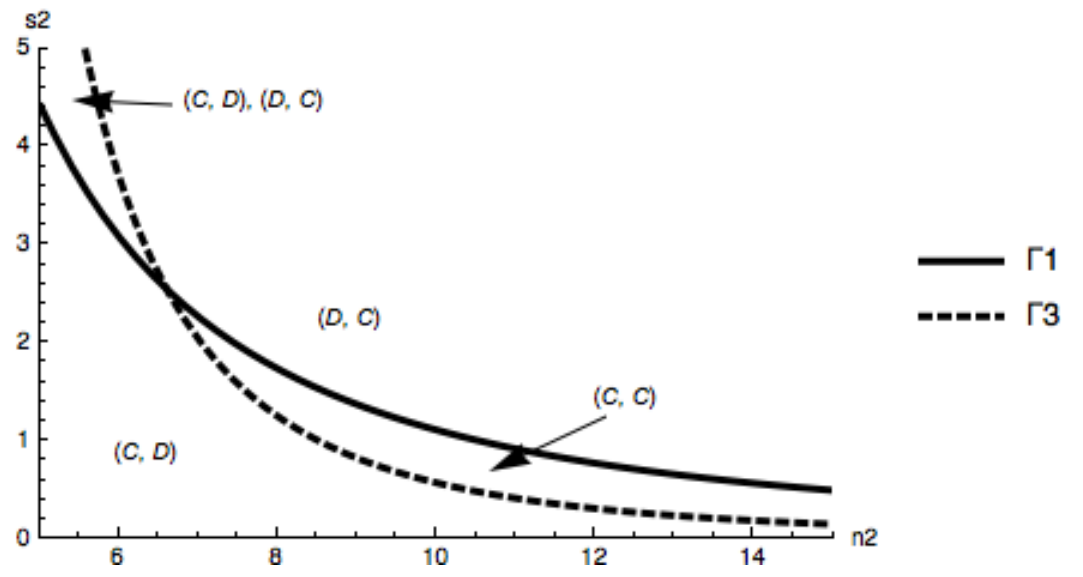

Figure 3: Equilibria of the simultaneous game with $\alpha=\gamma=s_{1}=1, \beta=$ $.01, n_{1}=10$.

$\Gamma_{1},{ }^{7}$ centralization is the dominant strategy for federation 1. Above $\Gamma_{3}$, centralization is a dominant strategy for federation 2. In this case $\Gamma_{2}$ is very high and $\Gamma_{4}$ very low (see Figure 2), so that in the range we display in Figure 3 decentralization is never a dominant strategy. There are multiple pure-strategy equilibria $\{(C, D),(D, C)\}$ in between the curves to the left of the intersection. Federation 2 is smaller than federation 1, but has a much higher sensitivity to the public good. Hence, no federation has a dominant strategy. There is a unique equilibrium $(C, C)$ in between the curves to the right of the intersection, as both federations are of comparable size but none has a much different sensitivity than the other. Above the two curves, the unique equilibrium is $(D, C)$ : federation 1 free rides on federation 2. Centralization is a dominant strategy of federation 2 only as it is both very sensitive to the public good and large enough to actually provide it. Below the two curves, it is the opposite, $(C, D)$, since federation 1 cares more about the public good, or is so much larger than it is the only one able to provide it.

In Figure 4, all parameters are identical to those in Figures 2 and 3, except for a higher value of $-B^{\prime \prime}=\beta=0.015$. Since the marginal benefit of the provision of public good decreases more quickly, $(C, C)$ is never an equilibrium as the two curves do not intersect: there are multiple equilibria in the whole region between the two curves. As in the previous figures, $(D, D)$ is never an equilibrium. It is however possible to show that for much higher values of $\beta$ it is possible to have $(D, D)$ as an equilibrium.

\footnotetext{
${ }^{7}$ As we focus on the generic games, we study the area below and above the curves, while the curves themselves correspond to the non-generic case where players are indifferent.
} 


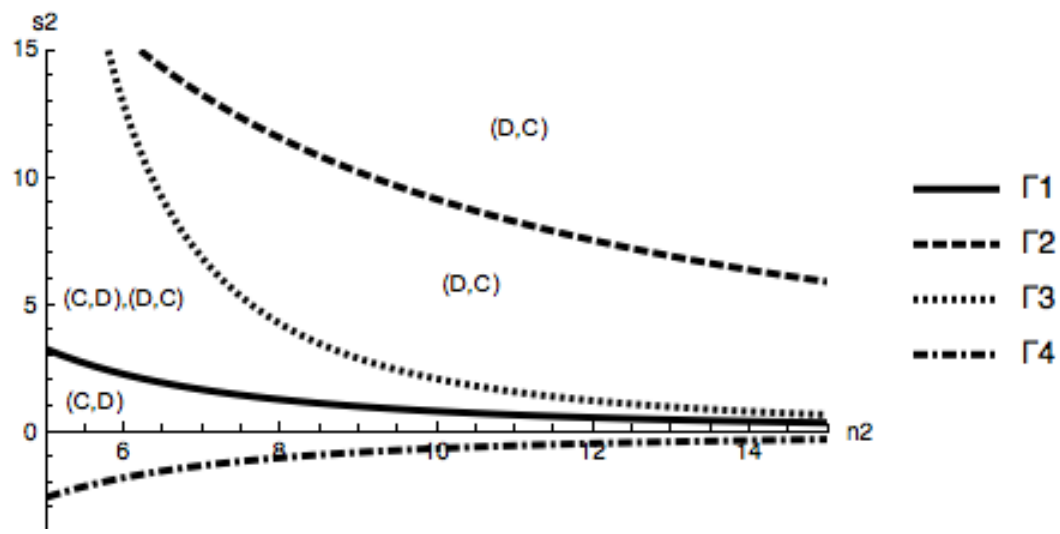

Figure 4: Equilibria of the simultaneous game with $\alpha=\gamma=s_{1}=1, \beta=$ $.015, n_{1}=10$

\subsection{Examples}

Let us end this section by two specific examples in the setting of Subsection 4.2. The first one illustrates the direct effects described in Proposition 1. The second illustrates the combination of the direct effects of Proposition 1 and the indirect effects of Proposition 2. In particular, we show that an increase in the sensitivity of all players may lead to a decrease in the aggregate production of the public good.

EXAMPLE 1: If there is only one federation centralizing at the unique equilibrium, it is the more sensitive federation among the two equal-sized ones that remains centralized.

Table 2 shows a case where at the unique equilibrium, federation 2 stays centralized while federation 1 chooses decentralization. The parameters are those for Figure 3. Two federations have the same size $\left(n_{1}=n_{2}=10\right)$, but federation 2 is more sensitive to the public good $\left(s_{2}=1.5\right)$. This therefore corresponds to a point in the center of Figure 3, above both curves.

Table 2: 2-federation decentralization game, $n_{1}=n_{2}=10, s_{1}=1, s_{2}=1.5$.

(a) Per-unit contributions

\begin{tabular}{l|c|c|}
\multicolumn{1}{c}{$C$} & \multicolumn{1}{c}{$D$} \\
\cline { 2 - 3 }$C$ & $2.9,4.3$ & $4.7,0.7$ \\
\cline { 2 - 3 }$D$ & $0.4,5.8$ & $0.8,1.2$ \\
\cline { 2 - 3 } & &
\end{tabular}

(b) Per-unit utilities

\begin{tabular}{l|c|c|} 
& \multicolumn{1}{c}{$C$} & \multicolumn{1}{c}{$D$} \\
\cline { 2 - 3 }$C$ & $4.2,6.0$ & $2.8,5.9$ \\
\cline { 2 - 3 }$D$ & $4.3 *, 4.7 *$ & $1.8,2.7$ \\
\cline { 2 - 3 } & &
\end{tabular}

In this example, the more sensitive federation 2 ends up producing more public good. The unique equilibrium of the game provides the second highest level of aggregate welfare of the first stage subgame. The highest one, excluding full cooperation that we rule out by assumption, is obtained 
when both federations are centralized. While there are inefficiencies, the predictions of this simultaneous game are fairly optimistic. If there is a unique equilibrium, we can expect it to correspond to the one where the centralized federation is also the one who is more willing (and able) to contribute to the public good. Returning to the different political structures of the United States and the European Union with respect to environmental policy and national defense, one could argue that the US cares more about global security while the EU cares more about climate change. The current political structure could also result from a decentralization game with multiple equilibria, which is only possible if both the sizes and the sensitivities to the public good of the two federations do not differ too much from each other.

EXAMPLE 2: Even if both federations become more sensitive to the public good, there can be less public good produced at the equilibrium.

The fact that the more sensitive a federation is to the public good, the fewer incentives it has for decentralization does not imply, however, that higher sensitivity always yields higher total contribution. In particular, the incentives for decentralization of the other federation also change. Compare the following two cases presented in Tables 3 and 4 . In Table 3, both federations have size 10 and sensitivity 1 , and all other parameters are the same as in Figure 3. Hence, it is situated in the area of Figure 3 where the unique equilibrium is $(C, C)$, and the total production of public good is $Q=66$.

Table 3: 2-federation decentralization game, $n_{1}=n_{2}=10, s_{1}=s_{2}=1$.

(a) Per-unit contributions

\begin{tabular}{l|c|c|} 
& \multicolumn{1}{c}{$C$} & \multicolumn{1}{c}{$D$} \\
\cline { 2 - 3 }$C$ & $3.3,3.3$ & $4.8,0.5$ \\
\cline { 2 - 3 }$D$ & $0.5,4.8$ & $0.8,0.8$ \\
\cline { 2 - 3 } & &
\end{tabular}

(b) Per-unit utilities

\begin{tabular}{c|c|c|}
\multicolumn{1}{c}{$C$} & \multicolumn{1}{c}{$C$} \\
\cline { 2 - 3 }$C$ & $3.9 *, 3.9 *$ & $2.7,3.8$ \\
\cline { 2 - 3 }$D$ & $3.8,2.7$ & $1.5,1.5$ \\
\cline { 2 - 3 } & &
\end{tabular}

Now, assume that the sensitivities to the public good are increased by $50 \%$ for both federations, so that $s_{1}=s_{2}=1.5$. The new game is presented by Table 4 . There are multiple equilibria. As a matter of fact, each federation knows that the other one cares enough about the public good to provide, even being the only centralized federation, a large amount of it. In comparison with Table 3, however, we remark that the aggregate amount of public good contributed at equilibrium is reduced after the rise of the sensitivities of both federations: $Q=63$.

This result is much more pessimistic than the previous example. It shows that, if a public good becomes particularly important in the sense that every player cares more about it, strategic effects on decentralization may 
Table 4: 2-federation decentralization game, $n_{1}=n_{2}=10, s_{1}=s_{2}=1.5$.

(a) Per-unit contributions

\begin{tabular}{c|c|c|}
\multicolumn{1}{c}{$C$} & \multicolumn{1}{c}{$D$} \\
\cline { 2 - 3 }$C$ & $3.7,3.7$ & $5.7,0.6$ \\
\cline { 2 - 3 }$D$ & $0.6,5.7$ & $1.2,1.2$ \\
\cline { 2 - 3 } & &
\end{tabular}

(b) Per-unit utilities

\begin{tabular}{c|c|c|} 
& \multicolumn{1}{c}{$C$} & \multicolumn{1}{c}{$D$} \\
\cline { 2 - 3 }$C$ & $6.3,6.3$ & $4.8 *, 6.4 *$ \\
\cline { 2 - 3 }$D$ & $6.4 *, 4.8 *$ & $3.0,3.0$ \\
\hline
\end{tabular}

do more than compensate for the higher individual incentives to provide the public good, so that the aggregate production is lower.

\section{Additional Results}

\subsection{Non-transferable utility}

In this section, we move to the case where utility is non-transferable within a federation. This polar case is discussed, in contrast to the fully transferable framework of the previous section, to illustrate the importance of monetary transfers within a federation in the choice of political structure. As shown by Bergstrom (1989), the assumption of TU within the federation is indeed necessary to assume that each member is interested in maximizing the aggregate utility of its members.

The following proposition outlines which member of a federation matters to the centralization decision.

Proposition 4. Suppose that the decentralization of one or several federations in $\mathcal{N}$, including federation $i$, result in a public goods game with equilibrium $\tilde{\mathbf{q}}$. Denote the gain in per-unit utility of two member countries $k$ and $l$ of federation $i$ after this decentralization by $\Delta_{k}=u_{k}(\tilde{\mathbf{q}})-v_{k}(\mathbf{q})$ and $\Delta_{l}=u_{l}(\tilde{\mathbf{q}})-v_{l}(\mathbf{q})$, respectively.

(i) If $s_{k}=s_{l}$, then $\Delta_{k}<\Delta_{l}$ if and only if $m_{k}>m_{l}$.

(ii) If $m_{k}=m_{l}$, then $\Delta_{k}<\Delta_{l}$ if and only if $s_{k}>s_{l}$.

Therefore, within a federation with equal sensitivity members, the larger a member country is, the more it gains from centralization; the smaller it is, the more it gains from decentralization. And within a federation with equal size members, the more sensitive a member country is, the more it gains from centralization; the less sensitive it is, the more it gains from decentralization.

In the scenario of NTU, we need to consider the decision rules that apply to a federation. A first possibility is the unanimity rule, according to which centralization is to be maintained only if all the members of the federation choose so. Equivalently, a single member's veto is enough for the federation 
to be decentralized. A second one is a (possibly qualified) majority rule, according to which centralization is to be maintained only if a majority of members chooses so. The first rule still applies to a number of decisions of the European Union, and is the case for any group of countries trying to transfer power to a new entity. The second rule corresponds to more integrated federations, in which an "upper house" represents the interest of each member. This is for instance the case of the US senate where each state receives two senators regardless of its population.

Corollary 3. Under full NTU,

- Suppose that unanimity rule is used to decide whether to maintain a centralized decision-making within a federation. If the member countries have the same sensitivity (resp. size), then the utility of the smallest country (resp. the country the least sensitive to the public good) is relevant to the decision.

- Suppose that majority rule is used to decide whether to maintain a centralized decision-making within a federation. If the $n$ member countries have the same sensitivity (resp. size), then the utility of the $\left[\frac{n-1}{2}\right]$ smallest countries (resp. the $\left[\frac{n-1}{2}\right]$ countries the least sensitive to the public good) are relevant to the decision. ${ }^{8}$

The proof follows directly from Proposition 4. This has implications on where NTU is relevant. If a vote is necessary to maintain the centralization of decision-making, the type of utility transfer that is necessary should be from bigger to smaller members, or from more sensitive to less sensitive members. It is also worth noting that what matters to a member country is not only its own size and sensitivity, but how it relates to the other members of the federation. For instance, a country with low sensitivity might be more opposed to being part of a centralized federation under NTU if the other members are particularly sensitive, because then it would need to contribute more in the last stage.

A first implication of this result is that heterogeneity in either sensitivity to a public good or size of the members can be a strategic advantage for a federation. Consider a variation of the example described in Table 2, in which member countries are identical and of size 1. Assume now that half of the members of federation 2 have sensitivity $s_{2}^{\prime}=1$, while the other half $s_{2}^{\prime \prime}=2$. The average sensitivity of the federation is thus still 1.5, like in Table 2. By equation (5), we know that the total production of public good in the federation - regardless of whether it is decentralized or not - is not affected by the heterogeneity of sensitivity of its members, for a given average sensitivity. Individual utility and individual contribution in the decentralized case are however affected.

\footnotetext{
${ }^{8}[x]$ is the largest integer that is not greater than $\mathrm{x}$.
} 
Table 5(a) reports the respective per-unit contribution of public good from the members of the two federations. Table 5(b) shows the per-unit utilities of the member countries, presented as $\left(u_{1},\left(u_{2}^{\prime}, u_{2}^{\prime \prime}\right)\right)$.

The game has multiple pure-strategy equilibria $\{(C, D),(D, C)\}$ if the federation uses either the unanimous rule or the majority rule to decide whether to maintain the centralization. In both cases, it is those members with sensitivity 1 who hold the decision. However, all members of federation 2 are better off at equilibrium $(C, D)$ than at $(D, C)$. Therefore, a federation can have a strategic advantage by being composed of heterogeneous members.

Table 5: Heterogeneity in sensitivity, $s_{2}^{\prime}=1, s_{2}^{\prime \prime}=2, s_{2}=1.5$.

(a) Per-unit contributions

(b) Per-unit utilities

\begin{tabular}{l|c|c|}
\multicolumn{1}{c}{$C$} & \multicolumn{1}{c}{$D$} \\
\cline { 2 - 3 }$C$ & $2.9,4.3$ & $4.7,0.7$ \\
\cline { 2 - 3 }$D$ & $0.4,5.8$ & $0.8,1.2$ \\
\cline { 2 - 3 } & &
\end{tabular}

\begin{tabular}{c|c|c|} 
& \multicolumn{1}{c}{$C$} & \multicolumn{1}{c}{$D$} \\
\cline { 2 - 3 }$C$ & $4.2,(3.7,8.3)$ & $2.8 *,(3.8,8.0) *$ \\
\cline { 2 - 3 }$D$ & $4.3 *,(2.6,4.3) *$ & $1.8,(1.4,4.1)$ \\
\cline { 2 - 3 } & &
\end{tabular}

Multiple equilibria with parameters identical to Table 2 but heterogeneous sizes among members of federation 2 can also be obtained. For instance, if five of its members have size $m_{2}^{\prime}=0.2$ and five have size $m_{2}^{\prime \prime}=1.8$, then the game has multiple equilibria. Table $6(\mathrm{a})$ reports the respective per-unit contribution of public good from the members of the federations, presented as $\left(q_{1},\left(q_{2}^{\prime}, q_{2}^{\prime \prime}\right)\right)$. Table $6(\mathrm{~b})$ shows the per-unit utilities of the members, presented as $\left(u_{1},\left(u_{2}^{\prime}, u_{2}^{\prime \prime}\right)\right)$. When federation 2 is centralized, the utility and contribution of each member of federation 2 are identical (see Lemma 1).

Table 6: Heterogeneity in size, $m_{2}^{\prime}=0.2, m_{2}^{\prime \prime}=1.8$.

\begin{tabular}{|c|c|c|c|c|}
\hline \multicolumn{2}{|c|}{ (a) Per-unit contributions } & \multicolumn{3}{|c|}{ (b) Per-unit utilities } \\
\hline C & $D$ & & $C$ & $D$ \\
\hline $2.9,4.3$ & $4.7,(0.1,1.2)$ & $C$ & $4.2,5.96$ & $3.0 *,(6.01,5.9) *$ \\
\hline $0.4,5.8$ & $0.8,(0.2,2.0)$ & $D$ & $4.3 *, 4.7 *$ & $2.2,(3.4,3.2)$ \\
\hline
\end{tabular}

Corollary 3 also implies that member countries becoming more sensitive to the public good may lead to a lower aggregate production of public good at equilibrium, for reasons different from Example 2 in Section 4.3. Consider a variant of the example in Table 2. Assume that half of the members of federation 2 now have a higher sensitivity $s_{2}^{\prime \prime}=3.5$ to the public good, while the other five still have sensitivity $s_{2}^{\prime}=1.5$. Hence, $s_{2}=2.5$. 
Table 7(a) displays the per-unit production of public good from the members of the two federations. Table $7(\mathrm{~b})$ shows the per-unit utilities of the member countries, presented as $\left(u_{1},\left(u_{2}^{\prime}, u_{2}^{\prime \prime}\right)\right)$. Comparing Table 7 (a) with Table 2(a), we first remark that the aggregate production of the public good is increased in each cell. This is a straightforward consequence of Lemma 2 which states that if the sensitivity of any player increases, the aggregate production increases in the public goods game. However, the increase is very marginal in the cell $(C, D)$, where federation 2 , the one that is more sensitive to the public good, unilaterally decentralizes. The reason is that the less sensitive federation 1 , albeit centralized, will not provide a lot of public good because it expects federation 2, albeit decentralized, to produce a large quantity.

Table 7: Heterogeneity in sensitivity, $s_{2}^{\prime}=1.5, s_{2}^{\prime \prime}=3.5, s_{2}=2.5$.
(a) Per-unit contributions
(b) Per-unit utilities

\begin{tabular}{c|c|c|}
\multicolumn{1}{c}{$C$} & \multicolumn{1}{c}{$D$} \\
\cline { 2 - 3 }$C$ & $2.2,5.6$ & $4.4,1.1$ \\
\cline { 2 - 3 }$D$ & $0.3,6.9$ & $0.7,1.9$ \\
\cline { 2 - 3 } & &
\end{tabular}

\begin{tabular}{c|c|c|}
\multicolumn{1}{c}{$C$} & \multicolumn{1}{c}{$D$} \\
\cline { 3 - 4 }$C$ & $4.5,(5.6,15.1)$ & $3.0 *,(5.7,14.6) *$ \\
\cline { 2 - 3 }$D$ & $4.6 *,(4.5,13.7) *$ & $2.2,(2.6,9.4)$ \\
\cline { 2 - 3 } &
\end{tabular}

Assume that either the majority rule or the unanimity rule is used to decide whether to maintain the centralization. The five less sensitive members of federation 2 hold the decision. According to Table 7, the game now has multiple equilibria. In particular, $(C, D)$ is now an equilibrium of the game, while it was not the case in Table 2. There are two reasons why the less sensitive members of federation 2 may now favor decentralization. First, being in a centralized federation with five fellow countries of very high sensitivity implies sharing more production of public good than in the example of Table 2. Second, being in a decentralized federation implies more benefits from free riding on the five fellow members of very high sensitivity.

Comparing the two examples, all countries are either as sensitive, or strictly more sensitive to the public good in Table 7 than in Table 2 . The economy however produces, in total, either strictly more public good $(Q=72$ for $(D, C)$ in Table 7$)$ or strictly less $(Q=55$ for $(C, D)$ in Table 7 ) than in Table 2 (where $Q=62$ ). This is because, for a given profile of political structure, federations always produce more public good in total when some countries become more sensitive. But the consequent heterogeneity in sensitivity within some federation(s) can lead a federation to strategically decentralize when utility is non-transferable. 


\subsection{Partial decentralization}

Unlike the literature on endogenous coalition formation, we discard in the basic models (in Section 4 and Subsection 5.1) the possibility that certain member countries of a federation form one or several smaller federations for two reasons. First, when a federation decentralizes the decision-making, it is natural to assume that this power is returned to the original component members of the federation instead of some newly formed sub-federation. We focus on the idea that players must be existing institutions, either an existing federation or an existing state or country. Second, even if we allow new sub-federations, they can either be created according to a joint decision of the decentralizing federation's members or come into existence through an endogenous coalition-formation process. We then need to consider the decision for each member country to join or leave the agreement, leading to the same incentives to free ride and the same results as the literature on self-enforcing IEAs.

As a robustness check, it is however possible to imagine the opposite polar case, in which a federation could delegate to sub-federations of any size if it is in the joint interest of its members to do so. Consider for instance a variant of Table 2 where, instead of a binary choice between centralization and full decentralization, federations can decentralize to any number of symmetric sub-federations of size $\frac{m_{i}}{x}$, where $x$ is an integer. This implies thus that we no longer have federation members of size 1, but any share of $m_{1}=m_{2}=10$ can be designed as a sub-federation.

Table 8 displays the relevant part of the per-unit utility matrix, denoting the size of sub-federations as $\frac{m_{i}}{x}$, so that $\frac{m_{1}}{2}$ means that federation 1 splits into two sub-federations, each of a size $\frac{m_{1}}{2}$. The smallest sub-federations are not displayed in the table for the sake of clarity, since they can be shown to be strictly dominated strategies. In each cell of the table are the per-unit utilities of the members of the two federations, according to the corresponding political structure. Note that both federations have homogenous members, and each chooses its political structure in order to maximize the total utility of its members, which is equivalent to maximizing their common per-unit utility.

Table 8: Utility matrix of a partial decentralization game, $s_{1}=1, s_{2}=1.5$.

\begin{tabular}{c|c|c|c|}
\multicolumn{1}{c}{} & \multicolumn{1}{c}{$m_{2}$} & $m_{2} / 2$ & $m_{2} / 3$ \\
\cline { 2 - 4 }$m_{1}$ & $4.18,5.97$ & $3.68,6.14$ & $3.40,6.10$ \\
\cline { 2 - 4 }$m_{1} / 2$ & $4.30,5.42$ & $3.77 *, 5.46 *$ & $3.44,5.31$ \\
$m_{1} / 3$ & $4.31 *, 5.16 *$ & $3.72,5.12$ & $3.35,4.90$ \\
$m_{1} / 4$ & $4.30,5.02$ & $3.67,4.92$ & $3.27,4.64$ \\
\cline { 2 - 4 } & &
\end{tabular}


This reduced normal-form decentralization game has two pure-strategy equilibria. At the first one, the less sensitive federation 1 decentralizes to three sub-federations, while the more sensitive federation 2 remains centralized. At the second one, both federations decentralize to two subfederations. The intuition that the more sensitive federation remains more often centralized still holds. Indeed, this is because Proposition 2(ii) is still valid in the case of partial decentralization. If two federations have the same size but different sensitivities, the less sensitive one is more willing to decentralize to any given size of a sub-federation. Similar to Example 2 in Subsection 4.3, we can also show that by doubling the sensitivity of both players to $s_{1}=2, s_{2}=3$, the game has a unique SPNE in which federation 1 decentralizes into three symmetric sub-federations while federation 2 decentralizes into two symmetric sub-federations. Hence, the intuition that higher sensitivity to the public good may lead to more decentralization remains valid.

Our focus on two polar cases therefore identifies the key mechanism generating the trade-off between centralization and decentralization. If partial decentralization is possible, however, we can expect to observe different degrees of decentralization instead of the clear-cut solutions of our main model.

\section{Conclusion}

Several federations of states and countries are active and relatively stable over time, and provide a large number of public goods in a centralized way. Some countries, on the contrary, will never be part of the same federation, because binding agreements including compensations and punishments involve a high level of mutual trust. The starting point of this paper is that while it would be relatively easy for existing federations to centralize their decision-making on global issues, this is not what they do in practice.

We show that one explanation to this phenomenon is that decentralization can be strategic if it benefits all the members of a federation. Such behavior acts as a commitment to free-riding. Decentralization therefore benefits a federation when the gain from free riding on other actors exceeds the loss caused by not internalizing the negative externalities exerted by its members on each other. While, all other things held equal, a federation that is relatively large or that cares relatively more about the public good should have more incentives to centralize, an overall increase in the sensitivity to the public good may actually lead to a lower aggregate production of it. The fact that sensitivity to the public good may hinder cooperation is reminiscent of results in the coalition-formation literature. For instance, in Barrett (1994), the number of members of an agreement decreases when the 
sensitivity to the public good increases. Hence, by taking the question of cooperation from the opposite perspective - federations choosing whether to centralize instead of players choosing whether to join an agreement - we end up identifying some rather similar problems.

In the presence of fully transferable utility, strategic effects are not affected by heterogeneity within the federation. This is not the case under non-transferable utility (NTU). We suggest that the strategic effects linked to NTU can help explaining the reluctance of the so-called BRICS (Brazil, Russia, India, China and South Africa) to establish a political institution, although they are holding annual meetings since 2009. While the five countries share similar concerns about "the international dominance of the United States, the threat of terrorism from religious fundamentalists and ethnic movements, and the need to prioritize economic development," they "remain reluctant to share any burdens" (Pant, 2013). Indeed, the only substantial cooperative institution launched by the BRICS is a joint development bank, making Rodrik (2013) write that "[what] the world needs from the BRICS is not another development bank, but greater leadership on today's great global issues. The BRICS countries are home to around half of the world's population and the bulk of unexploited economic potential. If the international community fails to confront its most serious challenges - from the need for a sound global economic architecture to addressing climate change - they are the ones that will pay the highest price." Observers often take the behavior of these countries as a sign of lack of interest in the global public goods. However, they may actually care much more than they appear to do. It is a largely documented fact (see, for instance, Bindoff et al., 2014, in the latest IPCC report) that the BRICS countries are expected to suffer much more from climate change than Europe or the United States. However, this effect is very heterogeneous. As BRICS countries may not have enough institutions and trust to organize monetary transfers, the effect we document above may help explaining the lack of advances in the BRICS as a federation.

Considering a sequential setting may lead to even less socially efficient results. By anticipating the future behavior of other federations, the larger or the more sensitive federation can prefer to choose to commit itself to decentralization (very much like the first-mover advantage in a Stackelberg game). Thus, going back to the BRICS example, before taking any significant step towards building institutions, they need to anticipate the impact of their decision on the strategic choices of existing federations. The real world timing is obviously not stricto sensu a sequential decentralization game in which the BRICS are the first group to choose its institutions, but if there is any chance that the European Union or the United States may be in a situation to revise their institutional structure in the near future, 
the first-mover advantage may be particularly relevant in understanding the incentives at play.

We voluntarily rule out the possibility of additional cooperation among federations, such as a "grand coalition" jointly deciding the level of public good. Large scale coalitions have the well-known problem that they need to be enforceable (see Chapter 15 of Barrett, 2005 or Nordhaus, 2015). A grand coalition would therefore need to be among players who have enough trust in each other or necessary institutions through which they can commit themselves to a certain level of public good. It is easy to see that assuming such trust would always lead to a grand coalition in a two-federation case. With several federations, the free-rider problem documented in the literature on IEA would remain, with multiple equilibria involving a small number of members.

Our static analysis does not embody the fact that, when institutions are built, actors do not necessarily anticipate every single future global issue. For instance, it is very likely that the founding fathers of the United States did not have climate change in mind at the time of drafting the constitution. What we claim is that, even in the presence of uncertainty, actors anticipate that building cooperative institutions may encourage the rest of the world to change its institutions accordingly, and thus generates more free-riders.

\section{Appendix A: Notations}

$\mathcal{N}$ : player set of a public goods game $G(\mathcal{N})$ : public goods game with player set $\mathcal{N}$

$\mathcal{F}$ : set of all the countries, including independent ones and members of federations

$n_{i}$ : number of member countries in federation $i$

$m_{i}$ : total size of federation $i$

$m_{k}$ : size of country $k$

$w_{k}$ : relative weight of country $k$ in federation $i$

$s_{k}$ : sensitivity of country $k$ to the public good

$M$ : total size of all the players

$\theta$ : square-weighted average sensitivity of all the players

$F_{i}$ : set of member countries of federation $i$

$Q_{i}$ : contribution of public good from player $i$

$q_{i}$ : per-unit contribution of player $i$

$Q$ : aggregate production of the public good

$v_{k}$ : per-unit utility of country $k$

$B(\cdot)$ : per-unit benefit from the aggregate production of the public good;

e.g. $B(Q)=\alpha Q-\frac{\beta}{2} Q^{2}$ 
$C(\cdot)$ : cost of providing the public good; e.g. $C(q)=\frac{\gamma}{2} q^{2}$

$V_{i}$ (resp. $v_{i}$ ): total (resp. per-unit utility) of federation $i$

$\mathcal{D}$ : two-stage decentralization game with players in $\mathcal{N}$

$\tilde{\mathcal{D}}$ : reduced (normal-form) decentralization game corresponding to the first

stage of $\mathcal{D}$, when only equilibrium behavior is considered in the second stage

$C$ : choice of centralization by a federation

$D$ : choice of decentralization by a federation

$a_{i}$ : strategy in the first stage of a decentralization game

$\mathcal{N}^{\mathrm{a}}$ : player set induced by the choices of (de)centralization made by players in $\mathcal{N}$

$u_{i}^{\text {a: }}$ average per-unit utility of federation $i$ in $\tilde{\mathcal{D}}$

\section{Appendix B: formal proofs}

Proof of Lemma 1. (i)-(ii): For federation $k$, given the total contribution from the other players $Q_{-i}$, its chooses $\left(q_{k}\right)_{k \in F_{i}}$ to maximize $v_{i}(\mathbf{q})=$ $\sum_{k \in F_{i}} w_{k} v_{k}(\mathbf{q})=\sum_{k \in F_{i}} w_{k}\left[s_{k} B(Q)-C\left(q_{k}\right)\right]=\sum_{k \in F_{i}} w_{k} s_{k} B(Q)-$ $\sum_{k \in F_{i}} w_{k} C\left(q_{k}\right)=s_{i} B\left(Q_{-i}+Q_{i}\right)-\sum_{k \in F_{i}} w_{k} C\left(q_{k}\right)$. Federation $i$ can solve the program in the following two steps. First, for any given value of $Q^{i}$, it minimizes $\sum_{k \in F_{i}} w_{k} C\left(q_{k}\right)$ subject to constraint $\sum_{k} w_{k} q_{k}=Q_{i} / m_{i}$. Since $C$ is a strictly convex function, we know by Jensen's inequality that $\sum_{k \in F_{i}} w_{k} C\left(q_{k}\right)$ is minimized when $q_{k}=Q_{i} / m_{i}$ for all $k \in F_{i}$. Second, federation chooses $Q_{i}$ to maximize $s_{i} B\left(Q_{-i}+Q_{i}\right)-C\left(Q_{i} / m_{i}\right)$.

(iii) Recall that $q_{i}=Q_{i} / m_{i}$ is the common per-unit contribution that federation $i$ imposes to its member countries. At any equilibrium $\mathbf{q}$, two member countries $k$ and $l$ of federation $i$ respectively have per-unit utility $v_{k}(\mathbf{q})=s_{k} B(Q)-C\left(q_{i}\right)$ and $v_{l}(\mathbf{q})=s_{l} B(Q)-C\left(q_{i}\right)$.

The following auxiliary result is used in several proofs.

Lemma 3. A Nash equilibrium $\mathbf{q}=\left(q_{1}, \ldots, q_{N}\right)$ of the public goods game satisfies that, for every player $i, q_{i}>0$ and $s_{i} m_{i} B^{\prime}(Q)=C^{\prime}\left(q_{i}\right)$.

Proof. It is simply a reformulation of the first order condition of the optimization problem (2).

Proof of Lemma 2. (i) Since each player's utility $v_{i}(\mathbf{q})$ is strictly concave in her own strategy $q_{i}$, the first order condition for (2) is necessary and sufficient. In other words, $\mathbf{q}$ is a Nash equilibrium if and only if for all player $i, s_{i} m_{i} B^{\prime}(Q)-C^{\prime}\left(q_{i}\right)<0$ if $q_{i}=0$ and $s_{i} m_{i} B^{\prime}(Q)-C^{\prime}\left(q_{i}\right)=0$ if $q_{i}>0$. This is equivalent to the variational inequality $\left\langle s_{i} m_{i} B^{\prime}(Q) \mathbf{1}-C^{\prime}(\mathbf{q}), \mathbf{q}^{\prime}-\mathbf{q}\right\rangle \leq 0$ for all $\mathbf{q}^{\prime} \in \mathbb{R}^{+N}$, i.e. $\sum_{i \in \mathcal{N}}\left(s_{i} m_{i} B^{\prime}(Q)-C^{\prime}\left(q_{i}\right)\right)\left(q_{i}^{\prime}-q_{i}\right) \geq 0$ for all $q_{i}^{\prime} \geq$ 
$0, i \in \mathcal{N}$. According to Corollary 4.3 in Kinderlehrer and Stampacchia, 2000 , this variational inequality admits a solution $\mathbf{q} \in \mathbb{R}^{+N}$.

The uniqueness of the equilibrium can be proved by contradiction. Suppose that $\mathbf{q}$ and $\mathbf{q}^{\prime}$ are two equilibria. Let us first show that $Q=Q^{\prime}$, where $Q=\sum_{i} m_{i} q_{i}$ and $Q^{\prime}=\sum_{i} m_{i} q_{i}^{\prime}$. If it is not true, say, for example, $Q>Q^{\prime}$, then $B^{\prime}(Q) \leq B^{\prime}\left(Q^{\prime}\right)$. According to Lemma 3, for each player $i$, $s_{i} m_{i} B^{\prime}(Q)=C^{\prime}\left(q_{i}\right)$, so that $q_{i} \leq q_{i}^{\prime}$. Therefore $\sum_{i} q_{i} \leq \sum_{i} q_{i}^{\prime}$, which is contradictory to the hypothesis that $Q>Q^{\prime}$. Therefore, $Q=Q^{\prime}$.

(ii) It is sufficient to notice that, at the equilibrium, $C^{\prime}\left(q_{i}\right)=s_{i} m_{i} B^{\prime}(Q)$ and $C^{\prime}\left(q_{j}\right)=s_{j} m_{j} B^{\prime}(Q)$.

(iii) Suppose that $m_{i}>m_{j}$ and $s_{i}=s_{j}$. Then by (ii) we know that $q_{i}>q_{j}$ at the equilibrium. Hence $u_{i}=s_{i} B(Q)-C\left(q_{i}\right)<u_{j}=s_{j} B(Q)-C\left(q_{j}\right)$.

(iv) Without loss of generality, assume that $m_{i}=m_{j}=1$ and $s_{i}>s_{j}$.

Recall that $s_{i} B^{\prime}(Q)=C^{\prime}\left(q_{i}\right)$ and $s_{j} B^{\prime}(Q)=C^{\prime}\left(q_{j}\right)$, which implies that $s_{i}-s_{j}=\frac{C^{\prime}\left(q_{i}\right)-C^{\prime}\left(q_{j}\right)}{B^{\prime}(Q)}$. Therefore, $u_{i}(\mathbf{q})>u_{j}(\mathbf{q})$ i.e. $s_{i} B(Q)-C\left(q_{i}\right)>$ $s_{j} B(Q)-C\left(q_{j}\right)$ if and only if $B(Q)>\frac{C\left(q_{i}\right)-C\left(q_{j}\right)}{s_{i}-s_{j}}=\frac{C\left(q_{i}\right)-C\left(q_{j}\right)}{C^{\prime}\left(q_{i}\right)-C^{\prime}\left(q_{j}\right)} B^{\prime}(Q)$ or still, $\frac{B(Q)}{B^{\prime}(Q)}>\frac{C\left(q_{i}\right)-C\left(q_{j}\right)}{C^{\prime}\left(q_{i}\right)-C^{\prime}\left(q_{j}\right)}$.

First let us show $\frac{B(Q)}{B^{\prime}(Q)} \geq q_{i}+q_{j}$. By the intermediate value theorem, $\frac{B(Q)}{Q}=\frac{B(Q)-B(0)}{Q}=B^{\prime}\left(Q_{0}\right)$ for some $Q_{0} \in[0, Q]$. Since $B$ is concave, one has $\frac{B(Q)}{Q} \geq B^{\prime}(Q)$ or equivalently $\frac{B(Q)}{B^{\prime}(Q)} \geq Q$. Evidently, $Q \geq q_{i}+q_{j}$; hence $\frac{B(Q)}{B^{\prime}(Q)} \geq q_{i}+q_{j}$.

Next let us show $q_{i}+q_{j}>\frac{C\left(q_{i}\right)-C\left(q_{j}\right)}{C^{\prime}\left(q_{i}\right)-C^{\prime}\left(q_{j}\right)}$, or equivalently $\frac{1}{q_{i}+q_{j}} \frac{C\left(q_{i}\right)-C\left(q_{j}\right)}{q_{i}-q_{j}}<$ $\frac{C^{\prime}\left(q_{i}\right)-C^{\prime}\left(q_{j}\right)}{q_{i}-q_{j}}$. By the intermediate value theorem, there exists $x \in\left[q_{j}, q_{i}\right]$ such that $\frac{C\left(q_{i}\right)-C\left(q_{j}\right)}{q_{i}-q_{j}}=C^{\prime}(x)=C^{\prime}(x)-C^{\prime}(0)$. Thus $\frac{1}{q_{i}+q_{j}} \frac{C\left(q_{i}\right)-C\left(q_{j}\right)}{q_{i}-q_{j}}<\frac{C^{\prime}(x)-C^{\prime}(0)}{x}$. It is easy to verify that function $\frac{C^{\prime}(x)-C^{\prime}(t)}{x-t}$ is increasing in $t$ on $[0, x]$ and $\frac{C^{\prime}(t)-C^{\prime}\left(q_{j}\right)}{t-q_{j}}$ is increasing in $t$ on $\left[q_{j}, q_{i}\right]$. Therefore $\frac{C^{\prime}(x)-C^{\prime}(0)}{x-0}<\frac{C^{\prime}(x)-C^{\prime}\left(q_{j}\right)}{x-q_{j}}<$ $\frac{C^{\prime}\left(q_{i}\right)-C^{\prime}\left(q_{j}\right)}{q_{i}-q_{j}}$.

(v) Suppose that $m_{i}$ increases and becomes $m_{i}^{\prime}>m_{i}$. Suppose that $Q^{\prime} \leq Q$. Then for player $j \neq i, C\left(q_{j}^{\prime}\right)=m_{j} s_{j} B^{\prime}\left(Q^{\prime}\right) \geq m_{j} s_{j} B^{\prime}(Q)=C\left(q_{j}\right)$, hence $q_{j}^{\prime} \geq q_{j}$. As a result, $m_{i}^{\prime} q_{i}^{\prime} \leq m_{i} q_{i}$ because $Q^{\prime} \leq Q$. Since $m_{i}^{\prime}>m_{i}$, one has $q_{i}^{\prime}<q_{i}$, and thus $m_{i}^{\prime} s_{i} B^{\prime}\left(Q^{\prime}\right)=C\left(q_{i}^{\prime}\right)<C\left(q_{i}\right)=m_{i} s_{i} B^{\prime}(Q)$. But $m_{i}^{\prime}>m_{i}$, then $B^{\prime}\left(Q^{\prime}\right)<B^{\prime}(Q)$, which contradicts the fact that $Q^{\prime} \leq Q$. Therefore $Q^{\prime}>Q$ and in consequence $q_{j}^{\prime}<q_{j}$ for every player $j \neq i$. This implies that $m_{i}^{\prime} q_{i}^{\prime}>m_{i} q_{i}$.

(vi) Suppose that $s_{i}$ increases and becomes $s_{i}^{\prime}>s_{i}$. Suppose that $Q^{\prime} \leq Q$. Then for player $j \neq i, C\left(q_{j}^{\prime}\right)=m_{j} s_{j} B^{\prime}\left(Q^{\prime}\right) \geq m_{j} s_{j} B^{\prime}(Q)=C\left(q_{j}\right)$, hence $q_{j}^{\prime} \geq q_{j}$. As a result, $q_{i}^{\prime} \leq q_{i}$ because $Q^{\prime} \leq Q$, and thus $m_{i} s_{i}^{\prime} B^{\prime}\left(Q^{\prime}\right)=$ $C\left(q_{i}^{\prime}\right) \leq C\left(q_{i}\right)=m_{i} s_{i} B^{\prime}(Q)$. But $s_{i}^{\prime}>s_{i}$, then $B^{\prime}\left(Q^{\prime}\right)<B^{\prime}(Q)$, which 
contradicts the fact that $Q^{\prime} \leq Q$. Therefore $Q^{\prime}>Q$ and in consequence $q_{j}^{\prime}<q_{j}$ for all player $j \neq i$. This implies that $q_{i}^{\prime}>q_{i}$.

Proof of Proposition 1. Recall that $\mathbf{q}$ is the equilibrium in the public goods game $G(\mathcal{N})$, and $Q=\sum_{j \in \mathcal{N}} m_{j} q_{j}$. Let $\mathbf{q}^{(i)}$ denote the equilibrium in public goods game $G\left(\mathcal{N}^{(i)}\right)$, which is induced by the unilateral decentralization of federation $i$, and let $Q^{(i)}=\sum_{j \in \mathcal{N}^{(i)}} m_{j} q_{j}^{(i)}$. The proposition can be reformulated as follows: (1) $Q^{(i)}<Q$; (2) for each $j \in \mathcal{N}$ and $j \neq i$, $q_{j}^{(i)}>q_{j}, u_{j}\left(\mathbf{q}^{(i)}\right)<u_{j}(\mathbf{q}) ;(3) \sum_{k \in F_{i}} w_{k} q_{k}^{(i)}<q_{i}$.

First notice that the member countries of federation $i$ provide the same quantity of public good at $\mathbf{q}^{(i)}$ since they are identical. Denote $q_{i}^{(i)}:=q_{k}^{(i)}$ for all $k \in F_{i}$.

(i) Suppose that $Q^{(i)} \geq Q$. For all $j \in \mathcal{N}$ and $j \neq i, C^{\prime}\left(q_{j}^{(i)}\right)=$ $s_{j} m_{j} B^{\prime}\left(Q^{(i)}\right) \leq s_{j} m_{j} B^{\prime}(Q)=C^{\prime}\left(q_{j}\right)$, thus $q_{j}^{(i)} \leq q_{j}$. Therefore $\sum_{k \in F_{i}} w_{k} q_{k}^{(i)}$ $\geq q_{i}$.

On the one hand, for all $k \in F_{i}, C^{\prime}\left(q_{k}^{(i)}\right)=s_{k} w_{k} m_{i} B^{\prime}\left(Q^{(i)}\right)$ hence $\sum_{k \in F_{i}} C^{\prime}\left(q_{k}^{(i)}\right)=\sum_{k \in F_{i}} s_{k} w_{k} m_{i} B^{\prime}\left(Q^{(i)}\right)=s_{i} m_{i} B^{\prime}\left(Q^{(i)}\right) \leq s_{i} m_{i} B^{\prime}(Q)=$ $C^{\prime}\left(q_{i}\right)$. We have thus proved that $\sum_{k \in F_{i}} C^{\prime}\left(q_{k}^{(i)}\right) \leq C^{\prime}\left(q_{i}\right)$. Recall that $q_{i} \leq \sum_{k \in F_{i}} w_{k} q_{k}^{(i)}$ which means $C^{\prime}\left(q_{i}\right) \leq C^{\prime}\left(\sum_{k \in F_{i}} w_{k} q_{k}^{(i)}\right)$. Therefore, $\sum_{k \in F_{i}} C^{\prime}\left(q_{k}^{(i)}\right) \leq C^{\prime}\left(\sum_{k \in F_{i}} w_{k} q_{k}^{(i)}\right)$. On the one hand, there must be some $l \in F_{i}$ such that $q_{l}^{(i)} \geq \sum_{k \in F_{i}} w_{k} q_{k}^{(i)}$. Hence $C^{\prime}\left(q_{l}^{(i)}\right) \geq C^{\prime}\left(\sum_{k \in F_{i}} w_{k} q_{k}^{(i)}\right) \geq$ $\sum_{k \in F_{i}} C^{\prime}\left(q_{k}^{(i)}\right)$. This is impossible, because $n_{i}>1$ hence $\sum_{k \in F_{i}} C^{\prime}\left(q_{k}^{(i)}\right)>$ $C^{\prime}\left(q_{l}^{(i)}\right)$.

We have thus proved that $Q^{(i)}<Q$.

(ii-iii) For any other player $j \neq i, C\left(q_{j}^{(i)}\right)=s_{j} m_{j} B^{\prime}\left(Q^{(i)}\right)>s_{j} m_{j} B^{\prime}(Q)=$ $C\left(q_{j}\right)$, hence $q_{j}^{(i)}>q_{j}$. As a result, $\sum_{k \in F_{k}} q_{k}^{(i)}<q_{i}$ because $Q^{(i)}<Q$. Besides, for $j \neq i, u_{j}=s_{j} B(Q)-C\left(q_{j}\right)>s_{j} B\left(Q^{(i)}\right)-C\left(q_{j}^{(i)}\right)=u_{j}^{(i)}$.

(iv) Suppose the common size of the member countries of federation $i$ (resp. $j$ ) is $\bar{m}_{i}\left(\bar{m}_{j}\right)$. Recall that $\bar{m}_{i} \leq \bar{m}_{j}$. For symmetric federation $i$, let $q_{i}^{(i)}$ denote the common per-unit contribution of member countries of federation $i$ after its decentralization, and let $q_{j}^{(j)}$ be similarly defined. (These notations and assumption are also used in the proof for (v) below.)

Let us prove: $Q^{(i)}<Q^{(j)}$. Suppose that $Q^{(i)} \geq Q^{(j)}$.

Let us first show that $m_{i} q_{i}^{(i)}+m_{j} q_{j}^{(i)} \geq m_{i} q_{i}^{(j)}+m_{j} q_{j}^{(j)}$. Case A: There are only two players, federations $i$ and $j$, in the game. Then $m_{i} q_{i}^{(i)}+m_{j} q_{j}^{(i)} \geq$ $m_{i} q_{i}^{(j)}+m_{j} q_{j}^{(j)}$ is equivalent to $Q^{(i)} \geq Q^{(j)}$. Case B: There are more than two players in the game. Consider player $l \neq i, j . C^{\prime}\left(q_{l}^{(i)}\right)=s_{l} m_{l} B^{\prime}\left(Q^{(i)}\right) \leq$ $s_{l} m_{l} B^{\prime}\left(Q^{(j)}\right)=C^{\prime}\left(q_{l}^{(j)}\right)$. Thus, $q_{l}^{(i)} \leq q_{l}^{(j)}$. In consequence, $\sum_{l \neq i, j} m_{l} q_{l}^{(i)} \leq$ $\sum_{l \neq i, j} m_{l} q_{l}^{(j)}$. But $Q^{(i)} \geq Q^{(j)}$, hence one deduces that $m_{i} q_{i}^{(i)}+m_{j} q_{j}^{(i)} \geq$ 
$m_{i} q_{i}^{(j)}+m_{j} q_{j}^{(j)}$, or equivalently $m_{i} q_{i}^{(j)}-m_{i} q_{i}^{(i)} \leq m_{j} q_{j}^{(i)}-m_{j} q_{j}^{(j)}$. Since $m_{i}>$ $m_{j}$, one has $q_{i}^{(j)}-q_{i}^{(i)}<q_{j}^{(i)}-q_{j}^{(j)}$ or equivalently $q_{j}^{(j)}-q_{i}^{(i)}<q_{j}^{(i)}-q_{i}^{(j)}$. But $q_{j}^{(i)}-q_{i}^{(j)}<0$ because $\frac{C^{\prime}\left(q_{j}^{(i)}\right)}{m_{j}}=s_{j} B^{\prime}\left(Q^{(i)}\right) \leq s_{i} B^{\prime}\left(Q^{(j)}\right)=\frac{C^{\prime}\left(q_{i}^{(j)}\right)}{m_{i}} \leq \frac{C^{\prime}\left(q_{i}^{(j)}\right)}{m_{j}}$ (recall that $s_{i}=s_{j}$ ). As a result, $q_{j}^{(j)}<q_{i}^{(i)}$.

However, $C^{\prime}\left(q_{i}^{(i)}\right)=s_{i} \bar{m}_{i} B^{\prime}\left(Q^{(i)}\right) \leq s_{j} \bar{m}_{j} B^{\prime}\left(Q^{(j)}\right)=C^{\prime}\left(q_{j}^{(j)}\right)$ which means that $q_{j}^{(j)} \geq q_{i}^{(i)}$. This is contradictory to the previous paragraph. Therefore $Q^{(i)}<Q^{(j)}$.

(v) Let us prove: $Q^{(i)}<Q^{(j)}$. Denote $m=m_{i}=m_{j}$. Suppose that $Q^{(i)} \geq Q^{(j)}$.

By the same argument as for (iv), one has $m q_{i}^{(i)}+m q_{j}^{(i)} \geq m q_{i}^{(j)}+m q_{j}^{(j)}$. Consequently $q_{i}^{(i)}-q_{j}^{(j)} \geq q_{i}^{(j)}-q_{j}^{(i)}>0$. The last inequality is because $\frac{C^{\prime}\left(q_{j}^{(i)}\right)}{m}=s_{j} B^{\prime}\left(Q^{(i)}\right)<s_{i} B^{\prime}\left(Q^{(j)}\right)=\frac{C^{\prime}\left(q_{i}^{(j)}\right)}{m}$ (recall that $s_{i}>s_{j}$ ). This further implies that $q_{j}^{(i)}-q_{j}^{(j)} \geq q_{i}^{(j)}-q_{i}^{(i)}>0$. The last inequality is because $q_{i}^{(j)}>q_{i}>q_{i}^{(i)}$.

On the other hand, recall that $C^{\prime}\left(q_{i}^{(j)}\right)-C^{\prime}\left(q_{j}^{(i)}\right)=s_{i} m B^{\prime}\left(Q^{(j)}\right)-s_{j} m B^{\prime}\left(Q^{(i)}\right)$ and $C^{\prime}\left(q_{i}^{(i)}\right)-C^{\prime}\left(q_{j}^{(j)}\right)=s_{i} \bar{m}_{i} B^{\prime}\left(Q^{(i)}\right)-s_{j} \bar{m}_{j} B^{\prime}\left(Q^{(j)}\right)$. Therefore $\left[C^{\prime}\left(q_{i}^{(j)}\right)-\right.$ $\left.C^{\prime}\left(q_{j}^{(i)}\right)\right]-n_{j}\left[C^{\prime}\left(q_{i}^{(i)}\right)-C^{\prime}\left(q_{j}^{(j)}\right)\right]>s_{i} m B^{\prime}\left(Q^{(j)}\right)-s_{j} m B^{\prime}\left(Q^{(i)}\right)-s_{i} m B^{\prime}\left(Q^{(i)}\right)+$ $s_{j} m B^{\prime}\left(Q^{(j)}\right)=\left(s_{i}+s_{j}\right) m\left[B^{\prime}\left(Q^{(j)}\right)-B^{\prime}\left(Q^{(i)}\right)\right]>0$.

Since $n_{j}>1$, one has $C^{\prime}\left(q_{i}^{(j)}\right)-C^{\prime}\left(q_{j}^{(i)}\right)>C^{\prime}\left(q_{i}^{(i)}\right)-C^{\prime}\left(q_{j}^{(j)}\right)>0$ and also $C^{\prime}\left(q_{i}^{(j)}\right)-C^{\prime}\left(q_{i}^{(i)}\right)>C^{\prime}\left(q_{j}^{(i)}\right)-C^{\prime}\left(q_{j}^{(j)}\right)>0$.

Suppose that $q_{j}^{(i)} \geq q_{i}^{(i)}$. By $C^{\prime}\left(q_{i}^{(j)}\right)-C^{\prime}\left(q_{j}^{(i)}\right)>C^{\prime}\left(q_{i}^{(i)}\right)-C^{\prime}\left(q_{j}^{(j)}\right)>0$ and $q_{i}^{(i)}-q_{j}^{(j)} \geq q_{i}^{(j)}-q_{j}^{(i)}>0$, one deduces that $\frac{C^{\prime}\left(q_{i}^{(j)}\right)-C^{\prime}\left(q_{j}^{(i)}\right)}{q_{i}^{(j)}-q_{j}^{(i)}}>\frac{C^{\prime}\left(q_{i}^{(i)}\right)-C^{\prime}\left(q_{j}^{(j)}\right)}{q_{i}^{(i)}-q_{j}^{(j)}}>$

0 . By the Intermediate Value Theorem, there exists $x \in\left[q_{j}^{(i)}, q_{i}^{(j)}\right]$ and $y \in\left[q_{j}^{(j)}, q_{i}^{(i)}\right]$ such that $\frac{C^{\prime}\left(q_{i}^{(j)}\right)-C^{\prime}\left(q_{j}^{(i)}\right)}{q_{i}^{(j)}-q_{j}^{(i)}}=C^{\prime \prime}(x), \frac{C^{\prime}\left(q_{i}^{(i)}\right)-C^{\prime}\left(q_{j}^{(j)}\right)}{q_{i}^{(i)}-q_{j}^{(j)}}=C^{\prime \prime}(y)$. Thus $C^{\prime \prime}(x)>C^{\prime \prime}(y)$. But $y \leq q_{i}^{(i)} \leq q_{j}^{(i)} \leq x$, hence $C^{\prime \prime}(x) \leq C^{\prime \prime}(y)$. This is impossible.

Suppose that $q_{j}^{(i)}<q_{i}^{(i)}$. By $C^{\prime}\left(q_{i}^{(j)}\right)-C^{\prime}\left(q_{i}^{(i)}\right)>C^{\prime}\left(q_{j}^{(i)}\right)-C^{\prime}\left(q_{j}^{(j)}\right)>0$ and $q_{j}^{(i)}-q_{i}^{(j)} \geq q_{i}^{(j)}-q_{i}^{(i)}>0$, one deduces that $\frac{C^{\prime}\left(q_{i}^{(j)}\right)-C^{\prime}\left(q_{i}^{(i)}\right)}{q_{i}^{(j)}-q_{i}^{(i)}}>\frac{C^{\prime}\left(q_{j}^{(i)}\right)-C^{\prime}\left(q_{j}^{(j)}\right)}{q_{j}^{(i)}-q_{j}^{(j)}}>$ 0 . Similarly, there must be $x \in\left[q_{i}^{(i)}, q_{i}^{(j)}\right]$ and $y \in\left[q_{j}^{(j)}, q_{j}^{(i)}\right]$ such that $\frac{C^{\prime}\left(q_{i}^{(j)}\right)-C^{\prime}\left(q_{i}^{(i)}\right)}{q_{i}^{(j)}-q_{i}^{(i)}}=C^{\prime \prime}(x), \frac{C^{\prime}\left(q_{j}^{(i)}\right)-C^{\prime}\left(q_{j}^{(j)}\right)}{q_{j}^{(i)}-q_{j}^{(j)}}=C^{\prime \prime}(y)$. Thus $C^{\prime \prime}(x)>C^{\prime \prime}(y)$. But $y \leq q_{j}^{(i)}<q_{i}^{(i)} \leq x$, hence $C^{\prime \prime}(x) \leq C^{\prime \prime}(y)$. This is impossible. 
Proof of Proposition 2. For federation $i$, set two constants: $\theta_{i} \triangleq \sum_{k \in F_{i}} w_{k}^{2} s_{k}$, and $\xi_{i} \triangleq \sum_{k \in F_{i}} w_{k}^{3} s_{k}^{2}$. Also set constants $m_{-i}=\sum_{j \in \mathcal{N} \backslash\{i\}} m_{j}$ and $\theta_{-i}=$ $\sum_{j \in \mathcal{N} \backslash\{i\}} s_{j}\left(\frac{m_{j}}{m_{-i}}\right)^{2}$.

With linear quadratic utility, one has

$$
\begin{aligned}
q_{i} & =\frac{\alpha m_{i} s_{i}}{\beta m_{i}^{2} s_{i}+\beta m_{-i}^{2} \theta_{-i}+\gamma}, \quad q_{j}=\frac{\alpha m_{k} s_{k}}{\beta m_{i}^{2} s_{i}+\beta m_{-i}^{2} \theta_{-i}+\gamma}, j \in \mathcal{N} \backslash\{i\}, \\
q_{k}^{(i)} & =\frac{\alpha m_{j} s_{j}}{\beta m_{i}^{2} \theta_{i}+\beta m_{-i}^{2} \theta_{-i}+\gamma}, k \in F_{i}, q_{j}^{(i)}=\frac{\alpha m_{i}^{2} \theta_{i}+\beta m_{-i}^{2} \theta_{-i}+\gamma}{\beta s_{i} m_{i}^{2}+\alpha \theta_{-i} m_{-i}^{2}}, \quad Q^{(i)}=\frac{\alpha \theta_{i} m_{i}^{2}+\alpha \theta_{-i} m_{-i}^{2}}{\beta \theta_{i} m_{i}^{2}+\beta \theta_{-i} m_{-i}^{2}+\gamma} \\
Q & =\frac{\beta s_{i} m_{i}^{2}+\beta \theta_{-i} m_{-i}^{2}+\gamma}{}
\end{aligned}
$$

(i) Federation 1 prefers decentralization to centralization if and only if $v_{1}=s_{i} B(Q)-C\left(q_{i}\right) \leq u_{1}^{(i)}=\sum_{k \in F_{i}} s_{k} w_{k} B\left(Q^{(1)}\right)-\sum_{k \in F_{i}} w_{k} C\left(q_{k}^{(i)}\right)$ or equivalently

$$
\begin{gathered}
\left(\beta s_{i} m_{i}^{2}+\gamma\right)\left[\left(\xi_{i}-\theta_{i}^{2}\right) \beta s_{i} m_{i}^{2}+\gamma\left(s_{i}^{2}-s_{i} \theta_{i}+\xi_{i}\right)\right] \leq \\
\left(s_{i}^{2}-\xi_{i}\right) \beta \theta_{-i} m_{-i}^{2}+2\left(\beta s_{i} m_{i}^{2}+\gamma\right)\left(s_{i} \theta_{i}-\xi_{i}\right) \beta \theta_{-i} m_{-i}^{2}
\end{gathered}
$$

Notice that $s_{i}=\sum_{k \in F_{i}} s_{k} w_{k}>\sum_{k \in F_{i}} s_{k} w_{k}^{2}$ because $w_{k} \leq 1$ for all $k$ and the inequality is strict for at least one $k$. Also, $s_{1} \theta_{1}-\xi_{1}=$ $\left(\sum_{k \in F_{1}} s_{k} w_{k}\right)\left(\sum_{k \in F_{1}} s_{k} w_{k}^{2}\right)-\sum_{k \in F_{1}} s_{k}^{2} w_{k}^{3}=\sum_{k \neq l} s_{k} w_{k} s_{l} w_{l}^{2}>0$ and $s_{1}^{2}-$ $\xi_{1}>s_{1} \theta_{1}-\xi_{1}>0$.

Hence, for fixed $s_{1}$ and $m_{1}$, the RHS of inequality (7) is strictly increasing both in $m_{-i}$ and $\theta_{-i}$.

(ii) If (7) is satisfied when federation $j$ is decentralized, then it must be satisfied when $j$ is centralized. To prove this, it is sufficient to show that the value of $\theta_{-i}$ therein when $j$ is centralized (denoted by $\theta_{-i}$ ) is greater than its value when $j$ is decentralized (denoted by $\theta_{-i}^{(j)}$ ), other things held equal. By definition,

$$
\begin{aligned}
m_{-i}^{2} \theta_{-i} & =\sum_{p \in \mathcal{N} \backslash\{i, j\}} s_{p} m_{p}^{2}+s_{j} m_{j}^{2}=\sum_{p \in \mathcal{N} \backslash\{i, j\}} s_{p} m_{p}^{2}+\left(\sum_{l \in F_{j}} s_{l} \frac{m_{l}}{m_{j}}\right) m_{j}^{2}, \\
m_{-i}^{2} \theta_{-i}^{(j)} & =\sum_{p \in \mathcal{N} \backslash\{i, j\}} s_{p} m_{p}^{2}+\sum_{l \in F_{j}} s_{l} m_{l}^{2},
\end{aligned}
$$

which implies that $m_{-i}^{2} \theta_{-i}-m_{-i}^{2} \theta_{-i}^{(j)}=\sum_{l \in F_{j}} s_{l} m_{l} m_{j}-\sum_{l \in F_{j}} s_{l} m_{l}^{2}=$ $\sum_{l \in F_{j}} s_{l} m_{l}\left(m_{j}-m_{l}\right)>0$.

Proof of Corollary 2. The result in Proposition 2(ii) shows that if $C$ is a best response to the other federation playing $C$, then $C$ is a dominant strategy, and if $D$ is a best response to the other playing $D, D$ is a dominant 
strategy. In particular, $(C, C)$ and $(D, D)$ cannot be both equilibria at the same time.

Proof of Proposition 3. For each fixed pair of $\left(n_{1}, s_{1}\right)$, let us consider the first quadrant of plan $\left(n_{2}, s_{2}\right)$ with $n_{2}$ on the horizontal axis and $s_{2}$ on the vertical axis. We trace four curves there: (i) $u_{1}^{C C}=u_{1}^{D C}$, (ii) $u_{1}^{C D}=u_{1}^{D D}$, (iii) $u_{2}^{C C}=u_{2}^{C D}$, (iv) $u_{2}^{D C}=u_{2}^{D D}$.

(i) $u_{1}^{C C}=u_{1}^{D C}$,

$$
\gamma \beta n_{1}^{3} s_{1}=\left(2 \beta n_{2}^{2} s_{2}+\gamma\right) \beta n_{1}^{2} s_{1}+\left(\beta^{2} n_{2}^{4} s_{2}^{2}-\gamma^{2}\right) n_{1}+\left(\beta n_{2}^{2} s_{2}+\gamma\right)^{2}
$$

Let us show that the curve is the graph of a function $\Gamma_{1}: \mathbb{R}^{++} \mapsto \mathbb{R}^{++}$, i.e. for each $n_{2}>0$, there is only one $s_{2}=\Gamma_{1}\left(n_{2}\right)>0$ satisfying (8). Indeed, for a fixed $n_{2}>0$, (8) implies

$$
\beta^{2}\left(1+n_{1}\right) n_{2}^{4} s_{2}^{2}+2 \beta\left(\beta n_{1}^{2} s_{1}+\gamma\right) n_{2}^{2} s_{2}-\left(\gamma \beta n_{1}^{2} s_{1}+\gamma^{2}\right)\left(n_{1}-1\right)=0 .
$$

$y\left(s_{2}\right)=\beta^{2}\left(1+n_{1}\right) n_{2}^{4} s_{2}^{2}+2 \beta\left(\beta n_{1}^{2} s_{1}+\gamma\right) n_{2}^{2} s_{2}-\left(\gamma \beta n_{1}^{2} s_{1}+\gamma^{2}\right)\left(n_{1}-1\right)$ is a convex parabola in coordinate system $\left(s_{2}, y\right)$. Its symmetric axis is $s_{2}=$ $-\frac{\left(\beta n_{1}^{2} s_{1}+\gamma\right)}{\beta\left(1+n_{1}\right) n_{2}^{2}}<0$. Moreover, for $s_{2}=0, y(0)=-\left(\gamma \beta n_{1}^{2} s_{1}+\gamma^{2}\right)\left(n_{1}-1\right)<0$. Therefore, the parabola has one and only one intersection with the strictly positive part of axis $s_{2}$, i.e. there is one and only one $s_{2}>0$ satisfying (8). Denote it by $\Gamma_{1}\left(n_{2}\right)$. We thus define function $\Gamma_{1}\left(n_{2}\right)$.

To decide the form of curve (8), we calculate the first and second derivatives of $\Gamma_{1}$. To this end, rewrite (8) to define function

$$
F\left(n_{2}, s_{2}\right)=\beta^{2}\left(1+n_{1}\right) n_{2}^{4} s_{2}^{2}+2 \beta\left(\beta n_{1}^{2} s_{1}+\gamma\right) n_{2}^{2} s_{2}-\left(\gamma \beta n_{1}^{2} s_{1}+\gamma^{2}\right)\left(n_{1}-1\right) .
$$

Then $F\left(n_{2}, \Gamma_{1}\left(s_{2}\right)\right) \equiv 0$. Denote by $\partial_{i} F$ the partial derivative of $F$ with respect to its $i$-th variable. Then $\partial_{1} F+\partial_{2} F \frac{\mathrm{d} \Gamma_{1}\left(n_{2}\right)}{\mathrm{d} n_{2}}=0$ which implies $\Gamma_{1}^{\prime}\left(n_{2}\right)=-\frac{\partial_{1} F}{\partial_{2} F}=-\frac{2 \Gamma_{1}\left(n_{2}\right)}{n_{2}}<0$ and consequently $\Gamma_{1}^{\prime \prime}\left(n_{2}\right)=\frac{6 \Gamma_{1}\left(n_{2}\right)}{n_{2}^{2}}>0$. Hence curve (8) is strictly decreasing and strictly convex.

It is easy to show that

$$
\Gamma_{1}\left(n_{2}\right)=\frac{\left(n_{1}-1\right) \sqrt{\beta n_{1}^{2} s_{1}+\gamma}}{\sqrt{\beta n_{1}^{2} s_{1}+\gamma n_{1}^{2}}+\sqrt{\beta n_{1}^{2} s_{1}+\gamma}} \cdot \frac{\gamma}{\beta n_{2}^{2}}
$$

For the area below curve $\Gamma_{1}, \gamma \beta n_{1}^{3} s_{1}>\left(2 \beta n_{2}^{2} s_{2}+\gamma\right) \beta n_{1}^{2} s_{1}+\left(\beta^{2} n_{2}^{4} s_{2}^{2}-\right.$ $\left.\gamma^{2}\right) n_{1}+\left(\beta n_{2}^{2} s_{2}+\gamma\right)^{2}$ hence $u_{1}^{C C}>u_{1}^{D C}$, it is better to for federation 1 to centralize when federation 2 centralizes. For the area above curve $\Gamma_{1}, \gamma \beta n_{1}^{3} s_{1}<\left(2 \beta n_{2}^{2} s_{2}+\gamma\right) \beta n_{1}^{2} s_{1}+\left(\beta^{2} n_{2}^{4} s_{2}^{2}-\gamma^{2}\right) n_{1}+\left(\beta n_{2}^{2} s_{2}+\gamma\right)^{2}$ hence 
$u_{1}^{C C}<u_{1}^{D C}$, it is better for federation 1 to decentralize when federation 2 centralizes.

(ii) $u_{1}^{C D}=u_{1}^{D D}$,

$$
\gamma \beta n_{1}^{3} s_{1}=\left(2 \beta n_{2} s_{2}+\gamma\right) \beta n_{1} s_{1}+\left(\beta^{2} n_{2}^{2} s_{2}^{2}-\gamma^{2}\right) n_{1}+\left(\beta n_{2} s_{2}+\gamma\right)^{2}
$$

which implies that

$$
\beta^{2}\left(1+n_{1}\right) n_{2}^{2} s_{2}^{2}+2 \beta\left(\beta n_{1} s_{1}+\gamma\right) n_{2} s_{2}-\left[\gamma \beta n_{1} s_{1}\left(n_{1}+1\right)+\gamma^{2}\right]\left(n_{1}-1\right)=0 .
$$

With the same methods employed for curve (8), we can show that curve (10) is the graph of a strictly positive valued function

$$
\Gamma_{2}\left(n_{2}\right)=\frac{\left(n_{1}-1\right)\left(\beta n_{1}^{2} s_{1}+\beta n_{1} s_{1}+\gamma\right)}{\sqrt{\beta n_{1} s_{1} \gamma\left(n_{1}^{3}+n_{1}^{2}+1\right)+\left(\beta^{2} s_{1}^{2}-\beta s_{1} \gamma+\gamma^{2}\right) n_{1}^{2}}+\beta n_{1} s_{1}+\gamma} \frac{\gamma}{\beta n_{2}}
$$

Its slope is $-\frac{\Gamma_{2}\left(n_{2}\right)}{n_{2}}<0$, and its second derivative is $\frac{2 \Gamma_{2}\left(n_{2}\right)}{n_{2}^{2}}>0$.

For the area below curve $\Gamma_{2}, u_{1}^{C D}>u_{1}^{D D}$, it is better for federation 1 to centralize (when federation 2 decentralizes). For the area above curve $\Gamma_{2}$, $u_{1}^{C D}<u_{1}^{D D}$, it is better for federation 1 to decentralize (when federation 2 decentralizes).

(iii) $u_{2}^{C C}=u_{2}^{C D}$,

$$
\gamma \beta n_{2}^{3} s_{2}-\left(2 \beta n_{1}^{2} s_{1}+\gamma\right) \beta n_{2}^{2} s_{2}-\left(\beta^{2} n_{1}^{4} s_{1}^{2}-\gamma^{2}\right) n_{2}=\left(\beta n_{1}^{2} s_{1}+\gamma\right)^{2}
$$

For simplicity, denote $b=\beta n_{1}^{2} s_{1}-\gamma$. Note that $b+2 \gamma=\beta n_{1}^{2} s_{1}+\gamma>0$, $2 b+3 \gamma=2 \beta n_{1}^{2} s_{1}+\gamma>0$. Then (12) is rewritten as

$$
\beta \gamma n_{2}^{2}\left(n_{2}-\frac{2 b+3 \gamma}{\gamma}\right) s_{2}=(b+2 \gamma)\left[b n_{2}+(b+2 \gamma)\right] .
$$

Define function $\left.\tilde{\Gamma}_{3}:\right] 0,2 b+3 \gamma[\cup] 2 b+3 \gamma,+\infty[\mapsto \mathbb{R}$ as follows:

$$
\tilde{\Gamma}_{3}\left(n_{2}\right)=\frac{b+2 \gamma}{\beta \gamma} \cdot \frac{b n_{2}+(b+2 \gamma)}{n_{2}^{2}\left(n_{2}-\frac{2 b+3 \gamma}{\gamma}\right)}
$$

Hence

$$
\tilde{\Gamma}_{3}^{\prime}\left(n_{2}\right)=\frac{2(b+2 \gamma)}{\beta \gamma n_{2}^{3}\left(n_{2}-\frac{2 b+3 \gamma}{\gamma}\right)^{2}}\left[-b n_{2}^{2}+\frac{b^{2}-3 \gamma^{2}}{\gamma} n_{2}+\frac{(2 b+3 \gamma)(b+2 \gamma)}{\gamma}\right]
$$

For later use, define function $g\left(n_{2}\right)=-b n_{2}^{2}+\frac{b^{2}-3 \gamma^{2}}{\gamma} n_{2}+\frac{(2 b+3 \gamma)(b+2 \gamma)}{\gamma}$, a quadratic parabola of $n_{2}$. 
Then

$$
\tilde{\Gamma}_{3}^{\prime}\left(n_{2}\right)=\frac{2(b+2 \gamma)}{\beta \gamma n_{2}^{3}\left(n_{2}-\frac{2 b+3 \gamma}{\gamma}\right)^{2}} \cdot g\left(n_{2}\right)
$$

Case A: $b=0$. Then $\tilde{\Gamma}_{3}\left(n_{2}\right)=\frac{4 \gamma}{\beta n_{2}^{2}\left(n_{2}-3\right)}, \tilde{\Gamma}_{3}^{\prime}\left(n_{2}\right)=-\frac{12 \gamma\left(n_{2}-2\right)}{\beta n_{2}^{3}\left(n_{2}-3\right)^{2}}$.

$\tilde{\Gamma}_{3}\left(n_{2}\right)$ is continuous and strictly negative over $] 0,3[$, continuous and strictly positive for $\left.n_{2} \in\right] 3,+\infty\left[\right.$, strictly increasing for $\left.\left.n_{2} \in\right] 0,2\right]$, strictly decreasing for $n_{2} \in\left[2,3\left[\right.\right.$, and strictly decreasing for $\left.n_{2} \in\right] 3,+\infty[$. Moreover, $\tilde{\Gamma}_{3}\left(n_{2}\right)$ goes to $-\infty$ both when $n_{2}$ goes to 0 from the right and when it goes to 3 from the left; $\tilde{\Gamma}_{3}\left(n_{2}\right)$ goes to $+\infty$ when $n_{2}$ goes to 3 from the right and $\tilde{\Gamma}_{3}\left(n_{2}\right)$ goes to 0 when $n_{2}$ goes to $+\infty$.

For $n_{2} \in\left[3,+\infty\left[\right.\right.$, for the area below the curve, $u_{2}^{C C}<u_{2}^{C D}$, it is better for federation 2 to decentralize (when federation 1 centralizes); for the area above the curve, $u_{2}^{C C}>u_{2}^{C D}$, it is better for federation 2 to centralize (when federation 1 centralizes). For $\left.n_{2} \in\right] 0,3$ [, for the area above the $n_{2}$-axis hence above the curve, $u_{2}^{C C}<u_{2}^{C D}$, it is better for federation 2 to decentralize (when federation 1 centralizes).

Case B: $b>0$. Rewrite $\tilde{\Gamma}_{3}\left(n_{2}\right)=\frac{b(b+2 \gamma)}{\beta \gamma} \cdot \frac{n_{2}+\frac{b+2 \gamma}{b}}{n_{2}^{2}\left(n_{2}-\frac{2 b+3 \gamma}{\gamma}\right)}$.

It is easy to show that $\frac{2 b+3 \gamma}{\gamma}>\frac{b^{2}-3 \gamma^{2}}{2 b \gamma}$ by simple algebra.

In order to know the form of $\tilde{\Gamma}_{3}\left(n_{2}\right)$, we look at its derivative (14).

Let us decide the sign of $g\left(n_{2}\right)$ over $] 0, \frac{2 b+3 \gamma}{\gamma}[$ and $] \frac{2 b+3 \gamma}{\gamma},+\infty[$. Note that the symmetric axis of the parabola is $\frac{b^{2}-3 \gamma^{2}}{2 b \gamma}<\frac{2 b+3 \gamma}{\gamma}$. Besides, $g(0)=$ $\frac{(2 b+3 \gamma)(b+2 \gamma)}{\gamma}>0, g(1)=\frac{3}{\gamma}(b+\gamma)^{2}>0, g\left(\frac{2 b+3 \gamma}{\gamma}\right)=-\frac{(2 b+3 \gamma)}{\gamma^{2}}(b+\gamma)^{2}<0$. Therefore there exists $\left.n_{2}^{+} \in\right] 1, \frac{2 b+3 \gamma}{\gamma}\left[\operatorname{such}\right.$ that $\tilde{\Gamma}_{3}^{\prime}\left(n_{2}\right)>0$ for $\left.n_{2} \in\right] 0, n_{2}^{+}[$, and $\tilde{\Gamma}_{3}^{\prime}\left(n_{2}\right)<0$ for $\left.n_{2} \in\right] n_{2}^{+},+\infty[$.

Thus we deduce that $\tilde{\Gamma}_{3}\left(n_{2}\right)$ is continuous and strictly negative over ]0, $\frac{2 b+3 \gamma}{\gamma}\left[\right.$, continuous and strictly positive for $\left.n_{2} \in\right] \frac{2 b+3 \gamma}{\gamma},+\infty[$, strictly increasing for $\left.\left.n_{2} \in\right] 0, n_{2}^{+}\right]$, strictly decreasing for $n_{2} \in\left[n_{2}^{+}, \frac{2 b+3 \gamma}{\gamma}[\right.$, and strictly decreasing for $\left.n_{2} \in\right] \frac{2 b+3 \gamma}{\gamma},+\infty\left[\right.$. Moreover, $\tilde{\Gamma}_{3}\left(n_{2}\right)$ goes to $-\infty$ both when $n_{2}$ goes to 0 from the right and when it goes to $\frac{2 b+3 \gamma}{\gamma}$ from the left; $\tilde{\Gamma}_{3}\left(n_{2}\right)$ goes to $+\infty$ when $n_{2}$ goes to $\frac{2 b+3 \gamma}{\gamma}$ from the right and $\tilde{\Gamma}_{3}\left(n_{2}\right)$ goes to 0 when $n_{2}$ goes to $+\infty$.

For $n_{2} \in\left[\frac{2 b+3 \gamma}{\gamma},+\infty\left[\right.\right.$, for the area below the curve, $u_{2}^{C C}<u_{2}^{C D}$, it is better for federation 2 to decentralize (when federation 1 centralizes); for the area above the curve, $u_{2}^{C C}>u_{2}^{C D}$, it is better for federation 2 to centralize (when federation 1 centralizes). For $\left.n_{2} \in\right] 0, \frac{2 b+3 \gamma}{\gamma}[$, for the 
area above the $n_{2}$-axis hence above the curve, $u_{2}^{C C}<u_{2}^{C D}$, it is better for federation 2 to decentralize (when federation 1 centralizes).

We can in fact incorporate Case A into Case B by noticing that when $b=0, n_{2}^{+}=2$.

Case C: $b<0$. Rewrite $\tilde{\Gamma}_{3}\left(n_{2}\right)=\frac{b(b+2 \gamma)}{\beta \gamma} \cdot \frac{n_{2}-\frac{b+2 \gamma}{-b}}{n_{2}^{2}\left(n_{2}-\frac{2 b+3 \gamma}{\gamma}\right)}$.

It is easy to show that $\frac{2 b+3 \gamma}{\gamma}<\frac{b^{2}-3 \gamma^{2}}{2 b \gamma}<\frac{b+2 \gamma}{-b}$ by simple algebra.

From (13), it is easy to see that $\tilde{\Gamma}_{3}\left(n_{2}\right)$ is continuous and strictly negative for $\left.n_{2} \in\right] 0, \frac{2 b+3 \gamma}{\gamma}\left[, \tilde{\Gamma}_{3}\left(n_{2}\right)\right.$ is continuous on $] \frac{2 b+3 \gamma}{\gamma},+\infty\left[, \tilde{\Gamma}_{3}\left(n_{2}\right)>0\right.$ for $\left.n_{2} \in\right] \frac{2 b+3 \gamma}{\gamma}, \frac{b+2 \gamma}{-b}\left[\right.$, and $\tilde{\Gamma}_{3}\left(n_{2}\right)<0$ for $\left.n_{2} \in\right] \frac{b+2 \gamma}{-b},+\infty[$.

In order to know the form of $\tilde{\Gamma}_{3}\left(n_{2}\right)$, we look at the derivative (14).

Let us decide the sign of $g\left(n_{2}\right)$ over $] 0, \frac{2 b+3 \gamma}{\gamma}[$ and $] \frac{2 b+3 \gamma}{\gamma},+\infty[$. Note that the symmetric axis of the parabola is $\frac{b^{2}-3 \gamma^{2}}{2 b \gamma}$. Besides, $g(0)=\frac{(2 b+3 \gamma)(b+2 \gamma)}{\gamma}>$ $0, g(1)=\frac{3}{\gamma}(b+\gamma)^{2}>0, g\left(\frac{2 b+3 \gamma}{\gamma}\right)=-\frac{(2 b+3 \gamma)}{\gamma^{2}}(b+\gamma)^{2}<0, g\left(\frac{b+2 \gamma}{-b}\right)=$ $\frac{b+2 \gamma}{b}(b+\gamma)^{2}<0$. Recall that $1<\frac{2 b+3 \gamma}{\gamma}<\frac{b^{2}-3 \gamma^{2}}{2 b \gamma}<\frac{b+2 \gamma}{-b}$. Therefore there exists $\left.n_{2}^{*} \in\right] 1, \frac{2 b+3 \gamma}{\gamma}\left[, n_{2}^{* *} \in\right] \frac{b+2 \gamma}{-b},+\infty\left[\right.$ such that $\tilde{\Gamma}_{3}^{\prime}\left(n_{2}\right)>0$ for $\left.n_{2} \in\right] 0, n_{2}^{*}[$ and $\left.n_{2} \in\right] n_{2}^{* *},+\infty\left[\right.$, and $\tilde{\Gamma}_{3}^{\prime}\left(n_{2}\right)$ for $\left.n_{2} \in\right] n_{2}^{*}, n_{2}^{* *}[$.

Moreover, $\tilde{\Gamma}_{3}\left(n_{2}\right)$ goes to $-\infty$ when $n_{2}$ goes to 0 from the right and when it goes to $\frac{2 b+3 \gamma}{\gamma}$ from the left; $\tilde{\Gamma}_{3}\left(n_{2}\right)$ goes to $+\infty$ when $n_{2}$ goes to $\frac{2 b+3 \gamma}{\gamma}$ from the right and $s_{2}$ goes to 0 when $n_{2}$ goes to $+\infty$.

For $n_{2} \in\left[\frac{2 b+3 \gamma}{\gamma}, \frac{b+2 \gamma}{-b}\left[\right.\right.$, for the area below the curve, $u_{2}^{C C}<u_{2}^{C D}$, it is better for federation 2 to decentralize (when federation 1 centralizes); for the area above the curve, $u_{2}^{C C}>u_{2}^{C D}$, it is better for federation 2 to centralize (when federation 1 centralizes). For $n_{2} \in\left[\frac{b+2 \gamma}{-b},+\infty\right.$, for the area above the $n_{2}$ axis, $u_{2}^{C C}>u_{2}^{C D}$, it is better for federation 2 to centralize (when federation 1 centralizes). For $\left.n_{2} \in\right] 0, \frac{2 b+3 \gamma}{\gamma}[$, for the area above the $n_{2}$-axis hence above the curve, $u_{2}^{C C}<u_{2}^{C D}$, it is better for federation 2 to decentralize (when federation 1 centralizes).

Finally, let us define a generalized function $\Gamma_{3}: \mathbb{R}^{++} \mapsto \mathbb{R}^{+} \cup\{+\infty\}$ as follows.

$$
\Gamma_{3}\left(n_{2}\right)= \begin{cases}+\infty, & \text { for } 0<n_{2} \leq \frac{2 b+3 \gamma}{\gamma}, \\ \max \left\{\frac{b+2 \gamma}{\beta \gamma} \cdot \frac{b n_{2}+(b+2 \gamma)}{n_{2}^{2}\left(n_{2}-\frac{2 b+3 \gamma}{\gamma}\right)}, 0\right\}, & \text { for } n_{2}>\frac{2 b+3 \gamma}{\gamma} .\end{cases}
$$

According to the analysis of the three cases (A, B, C), we know that for $n_{2} \in \mathbb{R}^{++}$, for the area below curve $\Gamma_{3}$ and above the horizontal $n_{2}$-axis, $u_{2}^{C C}<u_{2}^{C D}$, it is better for federation 2 to decentralize (when federation 1 centralizes); for the area above curve $\Gamma_{3}, u_{2}^{C C}>u_{2}^{C D}$, it is better for federation 2 to centralize (when federation 1 centralizes). 
(iv) $u_{2}^{D C}=u_{2}^{D D}$.

$$
\gamma \beta n_{2}^{3} s_{2}-\left(2 \beta n_{1} s_{1}+\gamma\right) \beta n_{2}^{2} s_{2}-\left(\beta^{2} n_{1}^{2} s_{1}^{2}-\gamma^{2}\right) n_{2}=\left(\beta n_{1} s_{1}+\gamma\right)^{2}
$$

The analysis for the form of curve (16) is almost the same as that for curve (12), simply by replacing $b$ by $a$, where $a=\beta n_{1} s_{1}-\gamma$.

In particular, we define a generalized function $\Gamma_{4}: \mathbb{R}^{++} \mapsto \mathbb{R}^{+} \cup\{+\infty\}$ as follows.

$$
\Gamma_{4}\left(n_{2}\right)= \begin{cases}+\infty, & \text { for } 0<n_{2} \leq \frac{2 a+3 \gamma}{\gamma}, \\ \max \left\{\frac{a+2 \gamma}{\beta \gamma} \cdot \frac{a n_{2}+(a+2 \gamma)}{n_{2}^{2}\left(n_{2}-\frac{2 a+3 \gamma}{\gamma}\right)}, 0\right\}, & \text { for } n_{2}>\frac{2 a+3 \gamma}{\gamma} .\end{cases}
$$

For $n_{2} \in \mathbb{R}^{++}$, for the area below curve $\Gamma_{4}$ and above the horizontal $n_{2}$-axis, $u_{2}^{D C}<u_{2}^{D D}$, it is better for federation 2 to decentralize (when federation 1 decentralizes); for the area above curve $\Gamma_{4}, u_{2}^{D C}>u_{2}^{D D}$, it is better for federation 2 to centralize (when federation 1 decentralizes).

Also note that $a<b$, hence if $a \geq 0$ then $b \geq 0$, and if $b<0$ then $a<0$.

According to (ii) of Proposition 2, curve $\Gamma_{1}$ is below curve $\Gamma_{2}$; curve $\Gamma_{4}$ is below curve $\Gamma_{3}$ on $\mathbb{R}^{++}$. In other words, for all $n_{2}>0, \Gamma_{1}\left(n_{2}\right)<\Gamma_{2}\left(n_{2}\right)$ and $\Gamma_{4}\left(n_{2}\right) \leq \Gamma_{3}\left(n_{2}\right)$.

Therefore, for a given quadruplet $\left(n_{1}, s_{1}, n_{2}, s_{2}\right)$, the equilibria of the corresponding two-stage simultaneous decentralization game $\mathcal{D}$ are decided by the $s_{2}$ 's relation with $\Gamma_{1}\left(n_{2}\right), \Gamma_{2}\left(n_{2}\right), \Gamma_{3}\left(n_{2}\right), \Gamma_{4}\left(n_{2}\right)$, respectively defined by (9), (11), (15) and (17).

More precisely,

- If $\Gamma_{3}\left(n_{2}\right)<s_{2}<\Gamma_{1}\left(n_{2}\right)$, then the unique equilibrium is $(C, C)$.

- If $\Gamma_{2}\left(n_{2}\right)<s_{2}<\Gamma_{4}\left(n_{2}\right)$, then the unique equilibrium is $(D, D)$.

- If $s_{2}<\min \left\{\Gamma_{2}\left(n_{2}\right), \Gamma_{4}\left(n_{2}\right)\right\}$, or if $s_{2}<\min \left\{\Gamma_{1}\left(n_{2}\right), \Gamma_{3}\left(n_{2}\right)\right\}$, then the unique equilibrium is $(C, D)$.

- If $s_{2}>\max \left\{\Gamma_{2}\left(n_{2}\right), \Gamma_{4}\left(n_{2}\right)\right\}$ or if $s_{2}>\max \left\{\Gamma_{1}\left(n_{2}\right), \Gamma_{3}\left(n_{2}\right)\right\}$, then the unique equilibrium is $(D, C)$.

- If $\max \left\{\Gamma_{1}\left(n_{2}\right), \Gamma_{4}\left(s_{2}\right)\right\}<s_{2}<\min \left\{\Gamma_{2}\left(n_{2}\right), \Gamma_{3}\left(n_{2}\right)\right\}$, then the equilibria are $(C, D)$ and $(D, C)$.

Proof of Proposition 4. According to Lemma 1.(ii), when federation $i$ is centralized, all its member countries have a common per-unit contribution $q_{i}$. 
(i) Since $s_{k}=s_{l}, u_{k}(\mathbf{q})=u_{l}(\mathbf{q})=s_{i} B(Q)-C\left(q_{i}\right)$. While federation $i$ is decentralized, Lemma 2 implies that $u_{k}(\tilde{\mathbf{q}})=s_{k} B(\tilde{Q})-C\left(\tilde{q}_{k}\right)<u_{l}(\tilde{\mathbf{q}})=$ $s_{l} B(\tilde{Q})-C\left(\tilde{q}_{l}\right)$ if and only if $m_{k}>m_{l}$.

(ii) $\left[u_{l}(\tilde{\mathbf{q}})-u_{l}(\mathbf{q})\right]-\left[u_{k}(\tilde{\mathbf{q}})-u_{k}(\mathbf{q})\right]=\left[u_{k}(\mathbf{q})-u_{k}(\tilde{\mathbf{q}})\right]-\left[u_{l}(\mathbf{q})-u_{l}(\tilde{\mathbf{q}})\right]=$ $\left[s_{k} B(Q)-C\left(q_{i}\right)-s_{k} B(\tilde{Q})+C\left(\tilde{q}_{k}\right)\right]-\left[s_{l} B(Q)-C\left(q_{i}\right)-s_{l} B(\tilde{Q})+C\left(\tilde{q}_{l}\right)\right]=$ $\left[s_{k}(B(Q)-B(\tilde{Q}))-\left(C\left(q_{i}\right)-C\left(\tilde{q}_{k}\right)\right)\right]-\left[s_{l}(B(Q)-B(\tilde{Q}))-\left(C\left(q_{i}\right)-C\left(\tilde{q}_{l}\right)\right)\right]=$ $\left(s_{k}-s_{l}\right)(B(Q)-B(\tilde{Q}))+\left(C\left(\tilde{q}_{k}\right)-C\left(\tilde{q}_{l}\right)\right)>0$ because $s_{k}>s_{l}, Q>\tilde{Q}$ (by Corollary 1) and $\tilde{q}_{k}>\tilde{q}_{l}$ (by Lemma 2 ).

\section{References}

Barnosky, A. D., Hadly, E. A., Bascompte, J., Berlow, E. L., Brown, J. H., Fortelius, M., Getz, W. M., Harte, J., Hastings, A., Marquet, P. A. et al. (2012). Approaching a state shift in earth's biosphere. Nature, 486 (7401), 52-58.

BARRETt, S. (1994). Self-enforcing international environmental agreements. Oxford Economic Papers, 46, 878-894.

- (2003). Environment and statecraft: The strategy of environmental treaty-making: The strategy of environmental treaty-making. Oxford University Press.

- (2005). The theory of international environmental agreements. Handbook of Environmental Economics, 3, 1457-1516.

Basile, A., Graziano, M. G. and Pesce, M. (2016). Oligopoly and cost sharing in economies with public goods. International Economic Review, 57 (2), 487-506.

Baye, M. R., Crocker, K. J. and Ju, J. (1996). Divisionalization, franchising, and divestiture incentives in oligopoly. The American Economic Review, 86 (1), 223-236.

Belleflamme, P. (2000). Stable coalition structures with open membership and asymmetric firms. Games and Economic Behavior, 30 (1), $1-21$.

Bergstrom, T., Blume, L. and Varian, H. (1986). On the private provision of public goods. Journal of Public Economics, 29 (1), 25-49.

Bergstrom, T. C. (1989). A fresh look at the rotten kid theorem-and other household mysteries. Journal of Political Economy, 97 (5), 1138 1159 . 
Bindoff, N. L., Stott, P. A., AchutaRao, M., Allen, M. R., Gillett, N., Gutzler, D., Hansingo, K., Hegerl, G., Hu, Y., JAIN, S. et al. (2014). Detection and attribution of climate change: from global to regional. In Climate Change 2013 - The Physical Science Basis, Cambridge University Press, pp. 867-952.

Bloch, F. (1996). Sequential formation of coalitions in games with externalities and fixed payoff division. Games and Economic Behavior, 14 (1), 90-123.

Buchholz, W., Cornes, R. and Rübbelke, D. (2014). Potentially harmful international cooperation on global public good provision. Economica, 81 (322), 205-223.

- and SAndler, T. (2016). Olson's exploitation hypothesis in a public good economy: a reconsideration. Public Choice, 168 (1-2), 103-114.

Carraro, C., Eyckmans, J. and Finus, M. (2006). Optimal transfers and participation decisions in international environmental agreements. The Review of International Organizations, 1 (4), 379-396.

- and Siniscalco, D. (1993). Strategies for the international protection of the environment. Journal of Public Economics, 52 (3), 309-328.

D'Aspremont, C., Jacquemin, A., Gabszewicz, J. J. and Weymark, J. A. (1983). On the stability of collusive price leadership. Canadian Journal of Economics, 16 (1), 17-25.

ECKERT, H. (2003). Negotiating environmental agreements: Regional or federal authority? Journal of Environmental Economics and Management, 46 (1), 1-24.

Gordon, P. H. (1997). Europe's uncommon foreign policy. International Security, 22 (3), 74-100.

Howorth, J. (2001). European defence and the changing politics of the European Union: hanging together or hanging separately? JCMS: Journal of Common Market Studies, 39 (4), 765-789.

Joskow, P. L., Schmalensee, R. and Bailey, E. M. (1998). The market for sulfur dioxide emissions. The American Economic Review, 88 (4), 669-685.

Kaldor, M. and SAlmon, A. (2006). Military force and European strategy. Survival, 48 (1), 19-34. 
Kinderlehrer, D. and Stampacchia, G. (2000). An Introduction to Variational Inequalities and Their Applications, Classics in Applied Mathematics, vol. 31. Philadelphia, PA: Society for Industrial and Applied Mathematics, reprint of the 1980 original.

Kirchner, E. J. (2006). The challenge of European Union security governance. JCMS: Journal of Common Market Studies, 44 (5), 947-968.

KÖKE, S. and LANGE, A. (2017). Negotiating environmental agreements under ratification constraints. Journal of Environmental Economics and Management, 83, 90-106.

Kosfeld, M., OkadA, A. and Riedl, A. (2009). Institution formation in public goods games. The American Economic Review, 99 (4), 1335-1355.

Lenton, T. M., Held, H., Kriegler, E., Hall, J. W., Lucht, W., Rahmstorf, S. and Schellnhuber, H. J. (2008). Tipping elements in the earth's climate system. Proceedings of the National Academy of Sciences, 105 (6), 1786-1793.

Lowe, P., Buller, H. and Ward, N. (2002). Setting the next agenda? British and French approaches to the second pillar of the Common Agricultural Policy. Journal of Rural Studies, 18 (1), 1-17.

Ludema, R. D. and Mayda, A. M. (2009). Do countries free ride on MFN? Journal of International Economics, 77 (2), 137-150.

Lutsey, N. and Sperling, D. (2008). America's bottom-up climate change mitigation policy. Energy Policy, 36 (2), 673-685.

Marchiori, C., Dietz, S. and Tavoni, A. (2017). Domestic politics and the formation of international environmental agreements. Journal of Environmental Economics and Management, 81, 115-131.

MCGinty, M. (2007). International environmental agreements among asymmetric nations. Oxford Economic Papers, 59 (1), 45-62.

Menon, A. (2011). European defence policy from Lisbon to Libya. Survival, 53 (3), 75-90.

Nordhaus, W. (2015). Climate clubs: overcoming free-riding in international climate policy. The American Economic Review, 105 (4), 1339 1370

OAtes, W. E. (2005). Toward a second-generation theory of fiscal federalism. International Tax and Public Finance, 12 (4), 349-373. 
Olson, M. and Zeckhauser, R. (1966). An economic theory of alliances. The Review of Economics and Statistics, 48 (3), 266-279.

PANT, H. V. (2013). The BRICS fallacy. The Washington Quarterly, $36(3), 91-105$.

RAY, D. and Vohra, R. (1997). Equilibrium binding agreements. Journal of Economic Theory, 73 (1), 30-78.

- and - (2001). Coalitional power and public goods. Journal of Political Economy, 109 (6), 1355-1385.

RoDrIK, D. (2013). What the world needs from the BRICS. Project Syndicate, April, 10.

Salant, S. W., Switzer, S. and Reynolds, R. J. (1983). Losses from horizontal merger: the effects of an exogenous change in industry structure on Cournot-Nash equilibrium. The Quarterly Journal of Economics, 98 (2), 185-199.

SorIn, S. and WAN, C. (2013). Delegation equilibrium payoffs in integersplitting games. RAIRO-Operations Research, 47 (1), 47-58.

YI, S.-S. (1997). Stable coalition structures with externalities. Games and Economic Behavior, 20 (2), 201-237. 